\title{
Current Synthetic Approaches to the Synthesis of Carbasugars from Non-Carbohydrate Sources
}

\author{
Alexandra Zorin ${ }^{1} \cdot$ Lukas Klenk $^{1} \cdot$ Tonia Mack $^{1} \cdot$ Hans-Peter Deigner ${ }^{1,2,3}$. \\ Magnus S. Schmidt ${ }^{1}$ (I)
}

Received: 2 November 2021 / Accepted: 24 January 2022 / Published online: 9 February 2022

(c) The Author(s) 2022

\begin{abstract}
Carbasugars are a group of carbohydrate derivatives in which the ring oxygen is replaced by a methylene group, producing a molecule with a nearly identical structure but highly different behavior. Over time, this definition has been extended to include other unsaturated cyclohexenols and carba-, di-, and polysaccharides. Such molecules can be found in bacterial strains and the human body, acting as neurotransmitters (e.g., inositol trisphosphate). In science, there are a wide range of research areas that are affected by, and involve, carbasugars, such as studies on enzyme inhibition, lectin-binding, and even HIV and cancer treatment. In this review article, different methods for synthesizing carbasugars, their derivatives, and similar cyclohexanes presenting comparable characteristics are summarized and evaluated, utilizing diverse starting materials and synthetic procedures.
\end{abstract}

Keywords Carbasugars · Carbohydrate chemistry $\cdot$ Synthesis $\cdot$ Pseudosugars

Magnus S. Schmidt

Magnus.Schmidt@hs-furtwangen.de

Alexandra Zorin

Alexandra.Zorin@hs-furtwangen.de

Lukas Klenk

Lukas.Klenk@hs-furtwangen.de

Tonia Mack

Tonia.Mack@hs-furtwangen.de

Hans-Peter Deigner

Hans-Peter.Deigner@hs-furtwangen.de

1 Medical and Life Sciences Faculty, Institute of Precision Medicine, Furtwangen University, Jakob-Kienzle-Str. 17, 78054 Villingen-Schwenningen, Germany

2 EXIM Department, Fraunhofer Institute IZI Leipzig, Schillingallee 68, 18057 Rostock, Germany

3 Faculty of Science, Associated Member of Tuebingen University, Auf der Morgenstelle 8, 72076 Tubingen, Germany 
<smiles>OCC1OC(O)C(O)C(O)C1O</smiles>

Carbohydrate

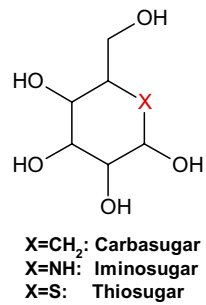

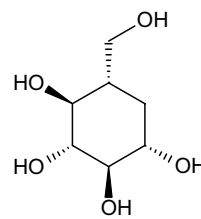

carba- $\beta$-L-glucose

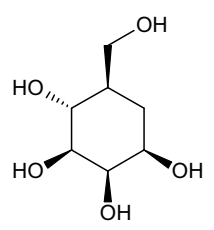

carba- $\beta$-D-idose

Scheme 1 Structural similarity between carbohydrates and pseudosugars, including examples for carba$\alpha$-L-galactopyranose, carba- $\beta$-L-glucopyranose and carba- $\beta$-D-idopyranose

\section{Introduction}

Carbohydrate chemistry is associated with a wide range of fields, such as organic chemistry, pharmaceuticals, medicine, and electrochemistry [1-3]. The broad range of functions of carbohydrate biomolecules, for example, the storage of energy, is made possible by the fact that carbohydrates are components of glycoproteins and glycolipids [4,5]. As components in these types of compounds, carbohydrates are involved in an extensive range of processes, such as signalling, cell-cell communication, and molecular and cellular targeting [6]. Further biological processes, such as blood clotting and fertilization, require carbohydrates, and the biological implications of these compounds are strongly related to diseases such as cancer, diabetes, and inflammatory processes [7].

Based on these factors, the search for new derivatives with analogous or even improved biological properties compared with those of the natural parent structures represent a logical focus of research. The term "carbohydrate mimetic" is used frequently to refer to any carbohydrate derivative or other compound that has multiple hydroxy groups and thereby resembles a saccharide. Between 1966 and 1968, the research group of McCasland developed a series of derivatives in which the ring oxygen of a monosaccharide was replaced by a methylene group; these authors neologized the term "pseudo sugars" for this family of compounds, though such compounds are currently called "carbasugars" (Scheme 1) [8, 9]. The researchers hypothesized that the structural resemblance of carbasugars to the original sugars would enable their identification by enzymes or other biological systems in place of the related true sugars. Importantly, while guaranteeing a high similarity with true natural sugars, the slight change affords compounds with greater stability toward endogenous degradative enzymes.

McCasland et al. synthesized 5a-carba-R-DL-talopyranose (the first reported carbasugar) [8], 5a-carba-R-DL-galactopyranose [10], and 5a-carba- $\alpha$-DLglucopyranose. Notably, 7 years later, 5a-carba-R-D-galactopyranose was isolated as a truly natural product from a fermentation broth of Streptomyces sp. [11]. In the following four decades, the chemical, biological, and conformational aspects of carbasugars were extensively studied $[12,13]$, resulting in studies on enzyme inhibition, lectin-binding, and even HIV and cancer treatment [14-16]. 
Various strategies have been employed for the synthesis and isolation of carbasugars, mostly starting from simple monosaccharides such as glucosamine and resulting in the corresponding carbasugars [17-19]. Other approaches work from simple hexopyranoses to more complex carbafuranoses such as carbaarabinofuranosides $[20,21]$ or even more complex carbasugar derivatives such as fluorinated carbasugars [22]. All these methods start from simple monosaccharidic compounds and require numerous synthetic steps to produce the final product [23-29]. In past years, scientists have developed and investigated possibilities for easily accessible alternative approaches. Starting with more basic chemical structures, a wide range of different strategies have been employed to achieve the goal of synthesizing carbasugars from non-carbohydrate sources.

Natural products containing carbasugar subunits fall beyond the scope of this review and will not be dealt with here, though their application in medicinal chemistry is of course important [11]. The chemical synthesis of carbasugars and their derivatives comprises the topic of this review. There are different approaches to these compounds, which are classified broadly into two groups: synthetic methods that use non-carbohydrates as starting materials, and procedures that make use of carbohydrates as precursors [12]. In pharmaceutical production, carbasugar synthesis is not being used, as it is based most dominantly on carbohydrate sources. Due to the complexity and inefficiency of the synthesis pathways, mass production of carbasugar-based pharmaceuticals is not feasible. Thus, a new type of carbomimetic synthesis is desired in order to ensure an efficient access to carbasugar production. Therefore, in this review, we concentrate on strategies that start from non-carbohydrate sources.

\section{Synthesis Methods}

The following sections will review six methods for synthesizing carbasugars from non-carbohydrate sources. The methods discussed are based on cylohexadiendiol, Norbornene, the Diels-Alder reaction, iodobenzene, methyl benzoate, or benzoquinone.

\subsection{Synthesis Based on Cyclohexadiendiol}

In this section, we analyze the synthesis of pseudosugars based on cyclohexadiendiol. The pericosines A (1), B (3), and C (4), shown in Scheme 2, occur naturally and were isolated originally from the fungus Periconia byssoides. This fungus can be found in the gastrointestinal tract of the sea hare Aplysia kurodai [30, 31]. The initial synthesis of pericosine was accomplished by Donohoe in 1998 [32]. Since then, interest in synthesizing pericosines has increased steadily.

Periscosines are known for their cytotoxicity against P388 lymphocytic leukaemia cells, antitumor activity against murine P388 cells, and selective growth inhibition against human cancer cell lines HBC-5 and SNB-75 [33]. By fulfilling these functions, pericosines may be important in treating cancer. In addition, the structural 


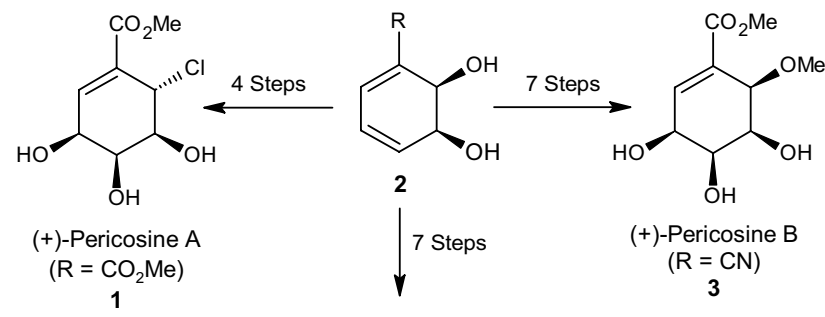<smiles></smiles>

(+)-Pericosine C $(\mathrm{R}=\mathrm{I})$

Scheme 2 The conversion of cis-dihydrocatechols into pericosines A, B, and C

similarities between pericosines (polyhydroxylated cyclohexenes) and pseudosugars (polyhydroxylated cyclohexanes) suggest that both could be classified as carbasugars [34].

Based on the reactions shown in Scheme 3, the dihydroxylation of cis-dihydrodiol 5, using the Donohoe procedure [35], gave a 4:1 mixture of two cis,cis-tetraol diastereoisomers. These diastereoisomers sequentially resulted from an oxidative attack on the same face at the 5,6 and 3,4 double bonds. Following the reaction in Scheme 3, the authors were able to isolate, after chromatography, regioisomer 6 with a $70 \%$ yield [34].

Furthermore, the authors theorized that the hydroxyl group at the C6 position of compound $\mathbf{6}$ would be less reactive in the subsequent acetal reaction because the C6 hydroxyl was hydrogen-bonded to the adjacent carbomethoxy group. Following

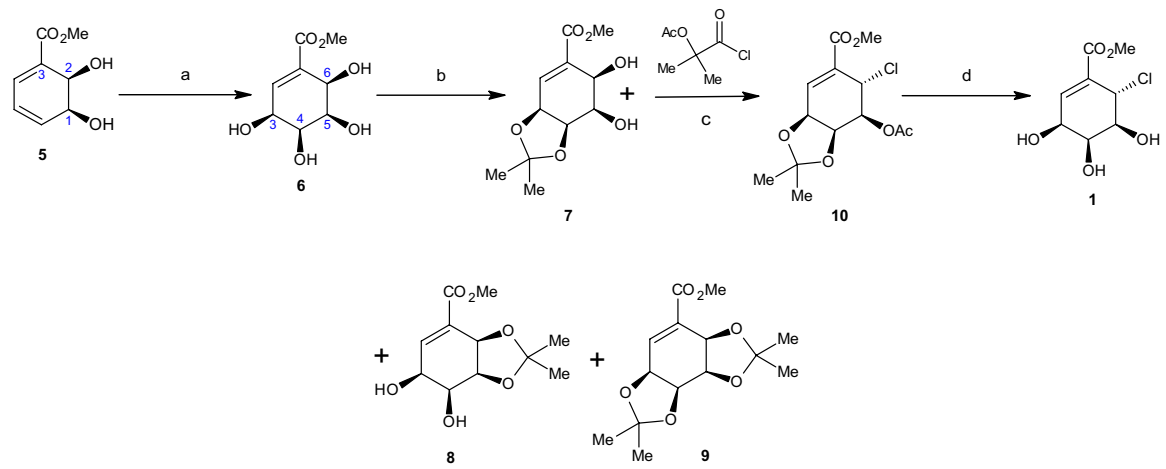

Scheme 3 Synthesis of pericosine A. Reagents and conditions: a OsO $\mathrm{O}_{4}, \mathrm{Me}_{3} \mathrm{NO}, \mathrm{CH}_{2} \mathrm{Cl}_{2}, \mathrm{rt}, 12 \mathrm{~h}(70 \%)$, b $\mathrm{Me}_{2} \mathrm{CO}, \mathrm{PTSA}, \mathrm{rt}, 12 \mathrm{~h}(74 \%), \mathbf{c ~ M e C N}, 0{ }^{\circ} \mathrm{C}, 15 \mathrm{~min}, \mathrm{rt}, 1 \mathrm{~h}(94 \%), \mathbf{d ~ M e O H}$, cat. $\mathrm{MeCOCl}, \mathrm{rt}, 12 \mathrm{~h}$ $(84 \%)$ 


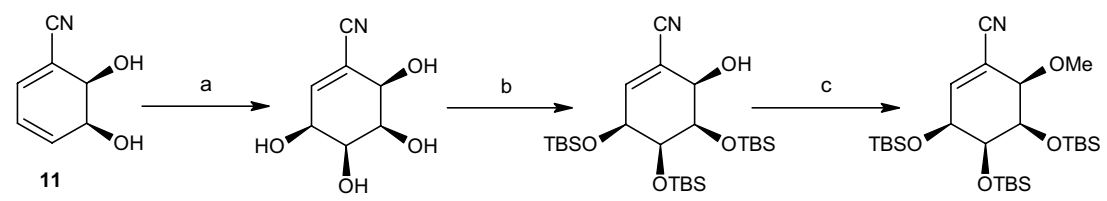

1213

14

d

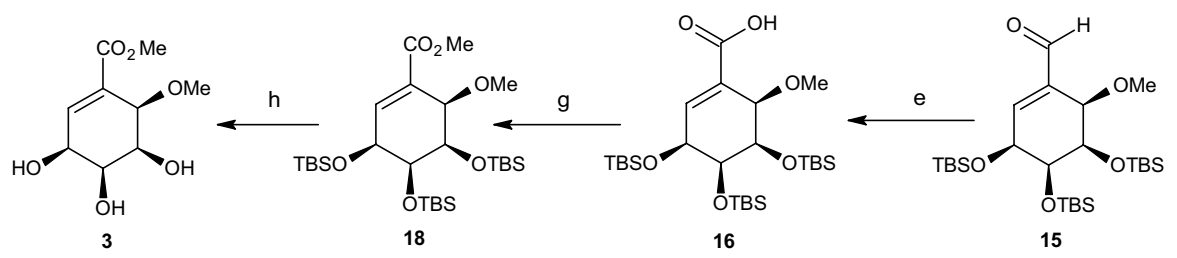

$\downarrow$

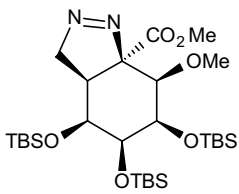

17

Scheme 4 Synthesis of pericosine B. Reagents and conditions: a $\mathrm{OsO}_{4}, \mathrm{Me}_{3} \mathrm{NO}, \mathrm{CH}_{2} \mathrm{Cl}_{2}, \mathrm{rt}, 48 \mathrm{~h}(55 \%)$, b TBSOTf, 2,6-lutidine, DMF, rt, 3 h (85\%), c NaH, Mel, THF, rt, 40 h (62\%), d DIBAL-H, Et 2 O, $0{ }^{\circ} \mathrm{C} \rightarrow \mathrm{rt}, 3 \mathrm{~h}(55 \%)$, e $\mathrm{NaClO}_{2}, t-\mathrm{BuOH}, \mathrm{NaH}_{2} \mathrm{PO}_{4}, \mathrm{rt}, 24 \mathrm{~h}(93 \%), \mathbf{f ~ C H}_{2} \mathrm{~N}_{2}, \mathrm{Et}_{2} \mathrm{O}, 30 \mathrm{~min}, 0{ }^{\circ} \mathrm{C} \rightarrow \mathrm{rt}$ (57\%), g Mel, $\mathrm{K}_{2} \mathrm{CO}_{3}, \mathrm{Me}_{2} \mathrm{CO}, 35{ }^{\circ} \mathrm{C}, 25 \mathrm{~min}(91 \%)$, h TFA $/ \mathrm{H}_{2} \mathrm{O}, \mathrm{CH}_{2} \mathrm{Cl}_{2}, \mathrm{rt}, 24$ h (90\%)

the reaction, tetraol $\mathbf{6}$ was treated at room temperature with acetone under acidic conditions, which resulted in a 7:4:9-mixture of acetonides 7, 8, and 9. There was no acetal formation between the hydroxyl groups at C4 and C5. Acetonide 7 (74\% overall yield) was produced by separating the mono- and bis-acetonides, repeatedly recycling the unwanted acetals $\mathbf{8}$ and $\mathbf{9}$ via hydrolysis, and reacetalizing the recovered tetraol 6 [34].

The authors also achieved synthesis of (+)-pericosine B (3) after hypothesizing that this form could be synthesized from tetraol 6. Synthesis was achieved after selective protection of the three hydroxyl groups on carbons $\mathrm{C} 3, \mathrm{C} 4$, and C5. To achieve the stated protection, the authors used the bulky TBS protecting group. However, the remaining hydroxyl group at C6 proved resistant to methylation under a broad range of conditions. Another way to accomplish this synthesis was to employ $(1 S, 2 R)$-3-cyanocyclohex-3-ene-1,2-diol 11 bearing a $\mathrm{CN}$ group that was less bulky than a $\mathrm{CO}_{2} \mathrm{Me}$ group (Scheme 4). By following the same steps used for the reaction of cis-dihydrodiols 5 and 19, the authors produced a 4:1 mixture of cis,cis- and cis,trans-tetraols in the dihydroxylation of diol 11. From this, the authors isolated the major cis, cis isomer 12 with a 54\% yield based on 


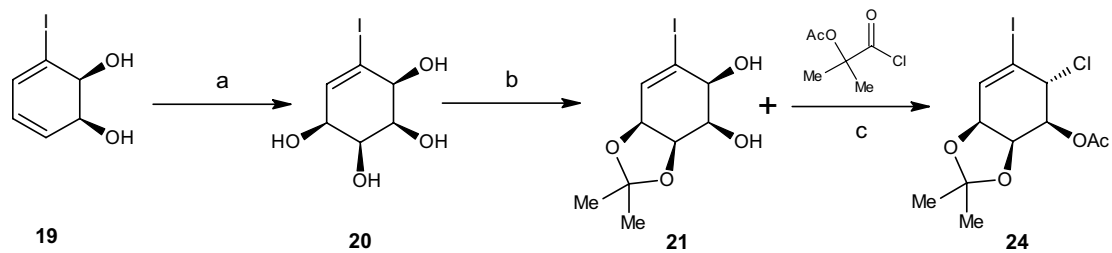<smiles>CO[C@H]1C(C(C)=O)=C[C@@H](O)[C@@H](O)[C@H]1O</smiles><smiles>CC1(C)O[C@H]2[C@@H](O)[C@H](O)C=C(I)[C@@H]2O1</smiles>

Scheme 5 Synthesis of pericosine C. Reagents and conditions: $\mathbf{a} \mathrm{OsO}_{4}, \mathrm{Me}_{3} \mathrm{NO}, \mathrm{CH}_{2} \mathrm{Cl}_{2}, \mathrm{rt}, 3 \mathrm{~d}(71 \%)$, b PTSA, $\mathrm{Me}_{2} \mathrm{CO}$, rt, $24 \mathrm{~h}(70 \%)$, c $\mathrm{MeCN}, 0{ }^{\circ} \mathrm{C}, 15 \mathrm{~min}, \mathrm{rt}, 1 \mathrm{~h}(95 \%)$, d NaOMe, $\mathrm{Et}_{2} \mathrm{O}, 0{ }^{\circ} \mathrm{C}, 15 \mathrm{~min}$, rt, 1 h (95\%), e NaOMe, $\mathrm{MeOH}, \mathrm{rt}, 12$ h (68\%), f NaOAc, $\mathrm{MeOH}, \mathrm{CO}, \mathrm{Pd}(\mathrm{OAc})_{2}, \mathrm{rt}, 12$ h $(89 \%), \mathbf{g}$ $\mathrm{MeOH}$,cat. $\mathrm{MeCOCl}, \mathrm{rt}, 12 \mathrm{~h}(80 \%)$

column chromatography. The reaction of tetraol 12 with tert-butyldimethylsilyl triflate produced the tri-TBS derivative $\mathbf{1 3}$ as the major product with $85 \%$ overall yield, together with small amounts of other unidentified inseparable isomers. The free C6 hydroxyl group of the coarse sample of silyl derivative $\mathbf{1 3}$ was then methylated, under mild conditions, and a purified sample of methyl ether 14 was isolated easily from the product mixture. The nitrile group in compound $\mathbf{1 4}$ was partially reduced to the aldehyde $\mathbf{1 5}$, followed by oxidation with sodium chlorite, resulting in 16. The authors then attempted to form the methyl ester $\mathbf{1 8}$ by reaction of carboxylic acid $\mathbf{1 6}$ with excess diazomethane. Instead of achieving the desired compound 18, the crystalline pyrazoline cycloadduct 17 resulted from this reaction. Thus, synthesis of compound $\mathbf{1 8}$ is achieved by base-mediated methylation of carboxylic acid 16, followed by acid-catalyzed removal of the TBS protecting groups, which produced (+)-pericosine B (3) through seven steps, with an overall yield of $12 \%$ [34].

To synthesize (+)-pericosine $\mathrm{C}(\mathbf{4})$, as shown in Scheme 5, the authors used $(1 S, 2 S)$-3-iodocyclohexa-3,5-diene-1,2-ol 19 as the starting material for the reaction. Under this alternative approach, cis-dihydrodiol 19 was dihydroxylized using the procedure in the literature (OsO4, TMNO, DCM) [34], thereby giving 
a 10:1 mixture of cis,cis- and cis,trans-tetraol diastereoisomers from which the required major cis,cis isomer $\mathbf{2 0}$ could be isolated with a $71 \%$ yield according to column chromatography. Through selective acetalization accomplished under kinetic control, along with repeated recycling of the unwanted acetals $\mathbf{2 2}$ and $\mathbf{2 3}$, the required acetal $\mathbf{2 1}$ was obtained with a $70 \%$ yield. The monoacetonide 22 formed upon partial hydrolysis of bis-acetonide $\mathbf{2 3}$, thereby giving access to both mono-protected forms of the tetraol (21 and 22). The reaction of diol 21 with 1-chlorocarbonyl-1-methylethyl acetate resulted in chloroacetate 24. Exposing 24 to sodium methoxide and diethyl ether, provided the desired epoxide $\mathbf{2 5}$. Further treatment of $\mathbf{2 5}$ with sodium methoxide in a methanol solution resulted in a regioselective ring opening thereby producing the methyl ether 26. Furthermore, room temperature palladium was used to catalyze carbomethoxylation of the vinyl iodide 26 with carbon monoxide in the methanol solution, which resulted in the methyl ester 27. Finally, the authors removed the acetonide group from ester 27 under acidic conditions in methanol, which produced (+)-pericosine $C(4)$. In the authors' opinion, this method of synthesizing (+)-pericosine C (4) is the most straightforward option to date, requiring only six steps from $(1 S, 2 S)$-3-iodocyclohexa-3, 5-diene-1,2-ol 19, with an overall yield of 17\% [34].

In conclusion, it was demonstrated that cis-dihydrodiols derived from methyl benzoate, iodobenzene, and cyanobenzene are versatile complementary intermediates for the rapid synthesis of pericosines A, C, and B, respectively.

Additionally, the laboratories used mutant strains (e.g., UV4, 39D) of the soil bacterium Pseudomonas putida and Escherichia coli, each containing toluene dioxygenase. This factor provided access to a vast range of over 400 metabolites [34].

The strategic approach for strains to produce 2,3-trans-CHD 28 can be compared to the work performed using Klebsiella pneumoniae strains. Non-pathogenic $E$. coli strains are common hosts for genetic modification because of the availability of potent E. coli mutants and their well-established fermentation conditions. In this way, previous studies acknowledged another host for synthesizing carbasugars [34, 36].

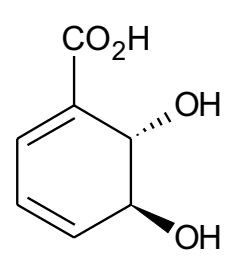

28

\subsection{Synthesis Based on Norbornene}

In this section, we analyze carbasugar synthesis based on norbornene, hereby covering only one paper reporting this approach. The structural entities of cyclitols and the polyhydroxylated cyclohexanoids compose important segments of a wide 
<smiles>OC[C@H]1C[C@H](O)[C@H](O)[C@H](O)[C@@H]1O</smiles>

29<smiles>O[C@H]1C=C[C@@H](O)[C@H](O)[C@H]1O</smiles>

30

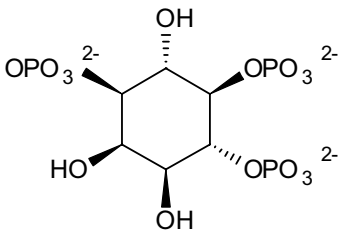

31<smiles>O=C1C(CO)=C[C@@H](O)[C@H](O)[C@@H]1O</smiles>

32

Scheme 6 Four polyhydroxylated cylcohexenoids: pseudo- $\alpha$-galactose (29), conduritol-A (30), myo-inositol 1,4,5-triphosphate (31) and gabosine-C (32)

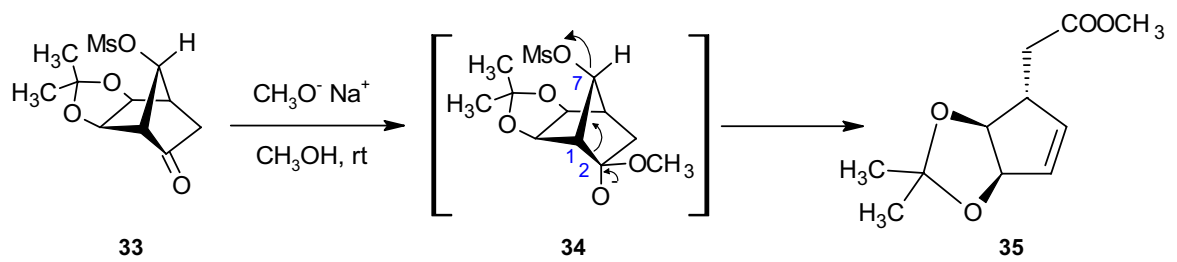

Scheme 7 Synthesis of acetonide compound $\mathbf{3 5}$

range of natural products, like antibiotics, and they exhibit biological activity profiles extending from glycosidase inhibitors to antidiabetes and anticancer agents. Better known examples for the mentioned cyclohexitols are the carbasugars. Examples would include pseudo-alpha-galactose (29), conduritol-A (30), myo-inositol 1,4,5-triphosphate (31), and gabosine-C (32) (Scheme 6).

To achieve the synthesis pathway for the carbasugars, the authors first used a 'bottom-to-top' Grob-like fragmentation process in an easily accessible 2,7-disubstituted norbornane derivative $\mathbf{3 3}$ to cleave the $\mathrm{C} 1-\mathrm{C} 2$ bond 34 . Furthermore, the process included extraction of the five-membered ring 35 from the bridged bicyclic frame while retaining full functionalization (see Scheme 7). Taking the paper under consideration, the authors developed a beneficial method for polyhydroxylated cyclohexenoid synthesis. In the following, polyhydroxylated cyclohexenoids are obtained from the same starting materials and subsequently interchanged with functional groups, thereby showing the possibility of extracting either five- or sixmembered rings from the norbornyl system [37].

In the cited paper, the authors tested a new approach that involved switching the functionalities in $\mathbf{3 3}$ to those in $\mathbf{3 6}$. By doing so, the authors arranged a "top-tobottom" sequence involving C7-C1 bond cleavage (see 37, Scheme 8) to deliver a functionally adorned cyclohexanoid $\mathbf{3 8}$ in a regio- and stereoselective manner [37].

To execute the approach shown in Scheme 8, clear access to 36 is needed. To ensure passage, the process in Scheme 9 was followed. Bicyclic alcohol 39, available from 5,5-dimethoxy-1,2,3,4-tetrachlorocyclopentadiene and vinyl acetate, was tosylated and exposed to $\mathrm{OsO}_{4}$-mediated catalytic dihydroxylation to yield exo,exodiol 40. By designing an amberlyst mediated single-pot protection-deprotection in 40, the authors achieved the 7-norbornanone derivative 41. By exposing 41 to 


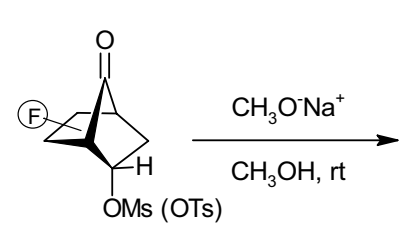

36

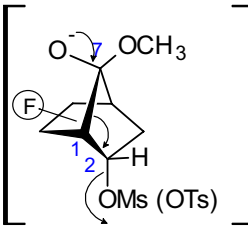

37

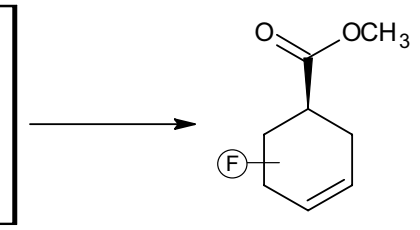

38

Scheme 8 Synthesis of the embellished cyclohexanoid 38

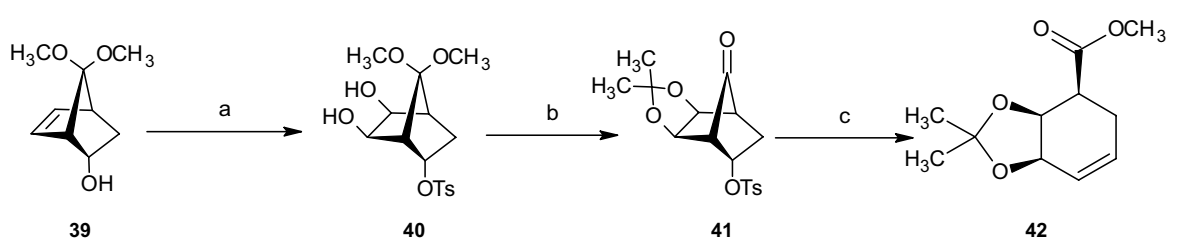

Scheme 9 Reagents and conditions. a i. TsCl, Py, DMAP, DCM, rt, 90\%; ii. OsO, NMMO, $\mathrm{Me}_{2} \mathrm{CO}: \mathrm{H} 2 \mathrm{O}$ (4:1), rt, 2 d, 84\%; b Amberlyst-15, aq. $\mathrm{Me}_{2} \mathrm{CO}$, rt, $90 \%$; c NaOMe, $\mathrm{MeOH}, \mathrm{rt}, 3$ h, $70 \%$

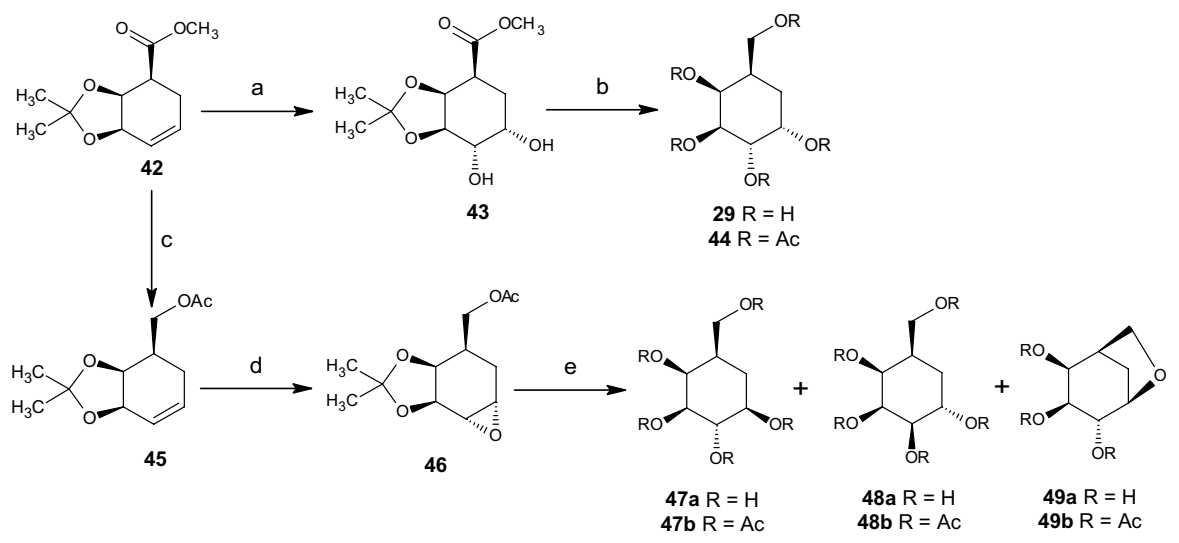

Scheme 10 Reagents and conditions. a $\mathrm{OsO}_{4}$, NMMO, 30 h, 95\%; b i. LAH, THF, rt, 88\%; ii. Amberlyst-15, aq. $\mathrm{MeOH}, 3$ h; iii. $\mathrm{Ac}_{2} \mathrm{O}, \mathrm{Py}, 20 \mathrm{~h}, 74 \%$ (two steps); c i. LAH, THF, $0-5{ }^{\circ} \mathrm{C}, 1 \mathrm{~h}, 90 \%$; ii. $\mathrm{Ac}_{2} \mathrm{O}$, DMAP, DCM, 95\%; d MCPBA, $\mathrm{Na}_{2} \mathrm{CO}_{3}$, DCM, 6 h, 65\%; e i. cat. $70 \% \mathrm{HClO}_{4}, \mathrm{H}_{2} \mathrm{O}, 30$ h; ii. $\mathrm{Ac}{ }_{2} \mathrm{O}, \mathrm{Py}$, $67 \%$ (two steps)

$\mathrm{NaOMe}$, the authors achieved smooth top-to-bottom fragmentation, yielding the cyclohexene methyl ester as a single product. The secured stereochemistry of the six ring carbons in cyclohexenoid $\mathbf{4 2}$ can be further elaborated to carbasugars [37].

Dihydroxylation across the C5-C6 double bond in cyclohexenoid ester $\mathbf{4 2}$ occurred through addition of osmium tetroxide, producing a large yield of cis-diol 43 in a stereoselective manner (Scheme 10). Lithium aluminium hydride (LAH) reduction of the ester group of $\mathbf{4 3}$, followed by acetonide deprotection provided the 

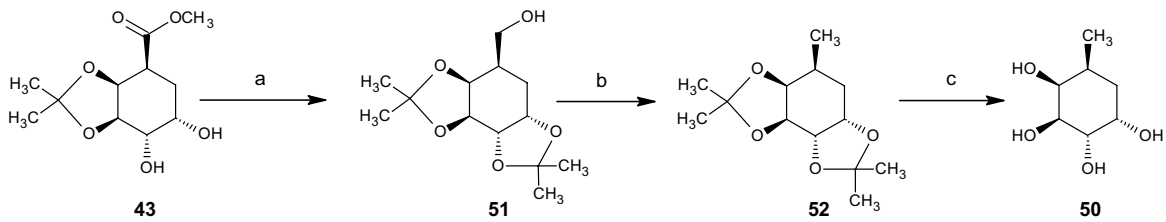

Scheme 11 Synthesis of pseudo- $\alpha$-fucopyranose; reagents and conditions. a $\mathrm{Me}_{2} \mathrm{CO}$, Amberlyst-15, mol. sieves 4 A , rt, 1 h, 85\%, LAH, THF, $0{ }^{\circ} \mathrm{C}, 2$ h, 82\%, b TsCl, Py, DCM, rt, 94\%, $\mathrm{NaBH}_{4}, \mathrm{DMSO}$, $70{ }^{\circ} \mathrm{C}, 6$ h, $72 \%$, c Amberlyst-15, aq. $\mathrm{MeOH}, \mathrm{rt}, 10$ h, $75 \%$

naturally occurring carbasugar pseudo- $\alpha$-galactose (29). This carbasugar was characterized as penta-acetate $\mathbf{4 4}$. Another method would involve the reduction of the ester group in $\mathbf{4 2}$ with LAH and acetylation, resulting in $\mathbf{4 5}$ (Scheme 10). To create $\mathbf{4 6}$, the carbon-carbon double bond of $\mathbf{4 5}$ must be converted to an oxirane (Scheme 10). In the study, acid-catalyzed epoxide ring-opening and naturally accompanying acetonide deprotection provided a 5:2:3 mixture of pseudo- $\beta$-galactose 47a, pseudo- $\alpha$ talose 48a, and bicyclic ether 49a, respectively. Those components of the mixture were well separated and characterized as the corresponding acetates, $\mathbf{4 7 b}, \mathbf{4 8 b}$, and 49b.

Finally, pseudo- $\alpha$-fucopyranose (50), which was synthesized from ester $\mathbf{4 2}$, showed a possible use as an inhibitor of fucosyltransferases. Due to this potential, the authors found another method for synthesizing $\mathbf{5 0}$. Instead of using $\mathbf{3 9}$ as a starting point, the authors used the diol ester $\mathbf{4 3}$ obtained from $\mathbf{4 2}$. This structure was converted into bis-acetonide and subjected to LAH reduction, yielding 51. Next, $\mathbf{5 1}$ was tosylated, and reductive detosylation using sodium borohydride was carried out in DMSO. This led to installation of the $\beta$-methyl group and bis-acetonide $\mathbf{5 2}$. Deprotection of $\mathbf{5 2}$ provided pseudo- $\alpha$-fucopyranose (50), which presented spectroscopic characteristics identical to those noted in previous research [37] (Scheme 11).

\subsection{Synthesis Based on Diels-Alder Reaction}

This reaction, named after its discoverers Diels and Alder from Kiel [38], involves the formation of a ring of six carbon atoms, wherein a conjugated diene and dienophile are linked. The importance of the Diels-Alder reaction is that $\mathrm{C}-\mathrm{C}$ bonds can be created with high stereoselectivity. Diels-Alder reactions play an important role in the synthesis of natural substances, such as the production of steroids (e.g., the female sex hormone estradiol). In this instance, the racemic cyclohexadiene derivative 53 reacted selectively in a catalytic enantioselective Nitroso-Diels-Alder reaction to give the two main products ent-anti-54 and anti-55, thereby showing the selective formation of two products from eight possible isomers (Scheme 12) [39].

The dienes used for cycloaddition were noted by the authors to be easily accessible, and the products were highlighted as valuable starting materials for the synthesis of carbasugars, such as peracetylated 2-epi-validamine (58, Scheme 15) [40]. It was hypothesized that divergent reactions from racemates are also possible in other Diels-Alder reactions of unsymmetrical dienophiles with racemic 
<smiles>[R]C1C=CC=CC1</smiles>

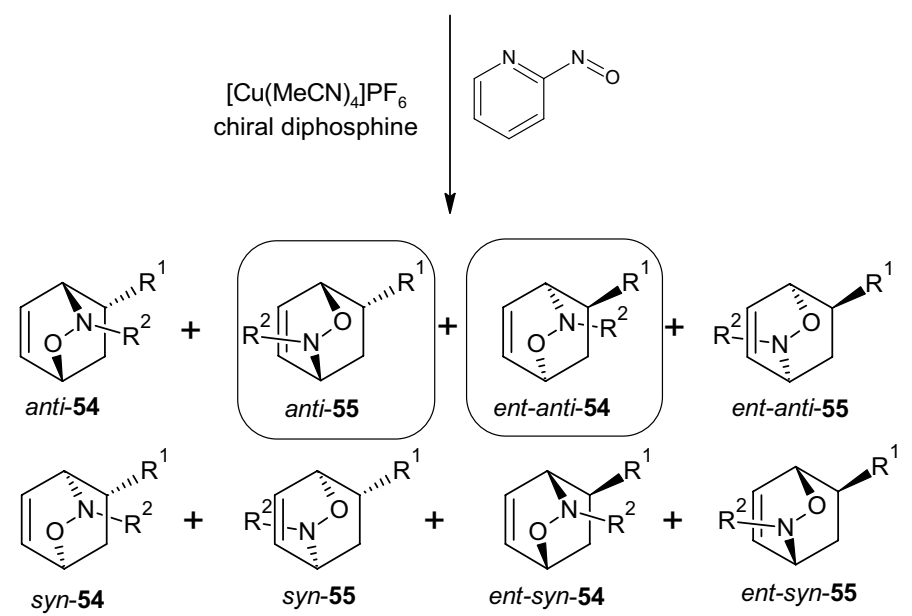

Scheme 12 Possible isomers that can be formed through the reaction of racemic diene $\mathbf{5 3}$ with an aryl nitroso compound. $\mathrm{R}^{1}=$ phenyl, alkyl; $\mathrm{R}^{2}=2$-pyridyl

cyclic dienes. This approach could lead to a new concept in the field of stereoselective cycloadditions [39].

A Nitroso-Diels-Alder reaction with the highly enantiomerically enriched diene 53a $(\mathrm{R}=(\mathrm{S})$-CHPhOTBDPS, 98\% ee) was then examined. The authors found that 53a could be produced easily by desymmetrizing 1,4-cyclohexadiene. At the same time, the ent-compounds in Scheme 12 were not considered. The formation of adducts 54a and 55a occurred in $\mathrm{CH}_{2} \mathrm{Cl}_{2}$ in the presence of $\left[\mathrm{Cu}(\mathrm{MeCN})_{4}\right]$ PF6 (10 mol\%), a chiral diphosphine (10 mol\%), and 2-nitrosopyridine $\left(6 \mathrm{~h}\right.$ at $-78{ }^{\circ} \mathrm{C}$ and then $12 \mathrm{~h}$ at $\left.-20{ }^{\circ} \mathrm{C}\right)$. The resulting two products, entanti-54a and ent-anti-55a, were produced in excellent yields (column chromatography, $\mathrm{SiO}_{2}$ ) and isolated with high enantiomeric excesses (see Scheme 13) [39].

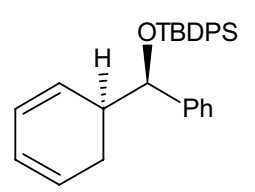

rac-53a
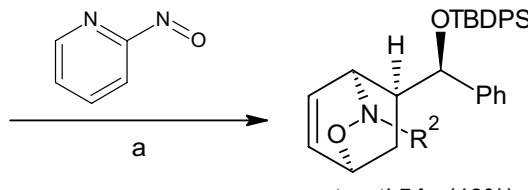

ent-anti-54a (48\%) $97 \%$ ee

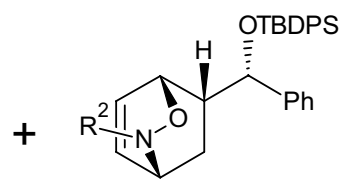

ent-anti-55a (52\%) $92 \%$ ee

Scheme 13 Nitroso-Diels-Alder reaction on the racemic diene 53a. Reagents and conditions: a $\left[\mathrm{Cu}(\mathrm{MeCN})_{4}\right] \mathrm{PF}_{6} /$ disphosphine $(10 \mathrm{Mol}-\%), \mathrm{CH}_{2} \mathrm{Cl}_{2},-78^{\circ} \mathrm{C} \rightarrow-20{ }^{\circ} \mathrm{C}$ 


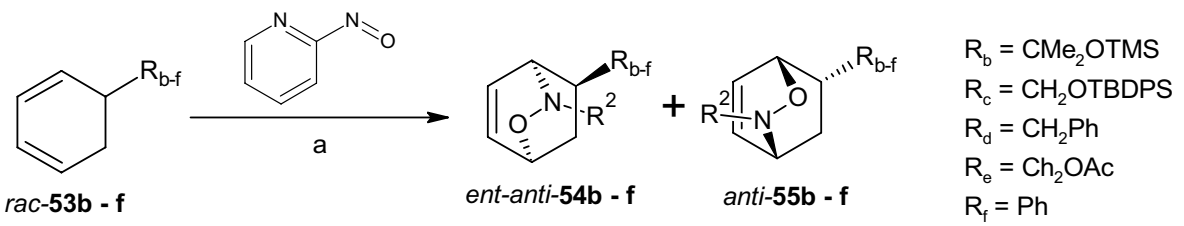

Scheme 14 Nitroso-Diels-Alder reaction with dienes 53b-e. Reagents and conditions: a $\left[\mathrm{Cu}(\mathrm{MeCN})_{4}\right]$ $\mathrm{PF}_{6} /$ disphosphine (10 mol-\%), $\mathrm{CH}_{2} \mathrm{Cl}_{2},-78^{\circ} \mathrm{C} \rightarrow-20^{\circ} \mathrm{C}$

Next, a Nitroso-Diels-Alder reaction was carried out with the racemic dienes 53b-f (Scheme 14). The implementation of 53b was successful and presented excellent anti/syn-selectivity. The adducts ent-anti-54b and anti-55b were developed with high enantioselectivities. The diene 53c showed poorer diastereoselectivity (anti/syn $=7: 1$ ) since the less sterically demanding $\mathrm{CH}_{2} \mathrm{OTBDPS}$ group represents a less efficient shield for the syn-side than the alpha-branched substituents. Similar results were observed for the benzyl-substituted diene 53d and the diene 53e, which carries an acetoxymethyl group. The best result was shown for the Ph-substituted diene 53f (see Scheme 14) [39].

Finally, the method presented above was used for the synthesis of peracetylated 2-epi-validamine (58). Reductive $\mathrm{N}-\mathrm{O}$-bond cleavage at ent-anti-55c (89\% ee), which was synthesized easily from rac-53c using an enantiomer of the Walphos ligand, with $\left[\mathrm{Mo}(\mathrm{CO})_{6}\right]$ and $\mathrm{NaBH}_{4}$, was followed by desilylation (TBAF) and subsequent acetylation, thereby producing the cyclohexadiene 56 (Scheme 15). Diastereoselective $\mathrm{OsO}_{4}$-catalyzed dihydroxylation and subsequent acetylation led to the pentaacetylated carbo-sugar 57. The N-2-pyridyl group was then cleaved using $\mathrm{H}_{2}$ and $\mathrm{Rh} / \mathrm{C}$, thus forming $\mathbf{5 8}$ [39].

Another approach for the synthesis of a racemate corresponding to validamine 65 was developed by Suami et al. [41, 42], whose approach was based on the Diels-Alder addition of furan to acrylic acid, resulting in oxanorbornene 59 (Scheme 16). Through hydrogenation in ethyl acetate and oxidation utilizing $\mathrm{H}_{2} \mathrm{O}_{2}$, an intermediate compound was achieved in $76 \%$ yield. Reduction and acetylation gave $69 \%$ of oxanorbornane $\mathbf{6 0}$, followed by acetolysis with $\mathrm{AcOH}$ and $\mathrm{H}_{2} \mathrm{SO}_{4}$, giving protected 5a-carba- $\beta$-DL-glucopyranose 61 (20\% yield). Deprotection of 61 resulted in 5a-carba- $\beta$-DL-glucopyranose (62). Reaction of compound 62 with DMP in dimethylformamide (DMF) in the presence of $p$ TSA and subsequent crystallization resulted in an inseparable 2:3 crystalline sulfonate mixture of compound $\mathbf{6 3}$ and 3-p-toluenesulfonate. Sodium azide in DMF caused creation of a new hexane compound from $\mathbf{6 3}$, while preserving the 3 -p-toluenesulfonate (11\%). Evaporation gave $67 \%$ of the new azide compound 64. Reduction with $\mathrm{H}_{2}$ in the presence of Raney nickel in ethanol, followed by acid hydrolysis of the protective groups resulted in the racemate corresponding to validamine $\mathbf{6 5}$. The racemate was isolated as penta-N,O-acetyl-DL-validamine (28\%, Scheme 16) [41, 42]. 

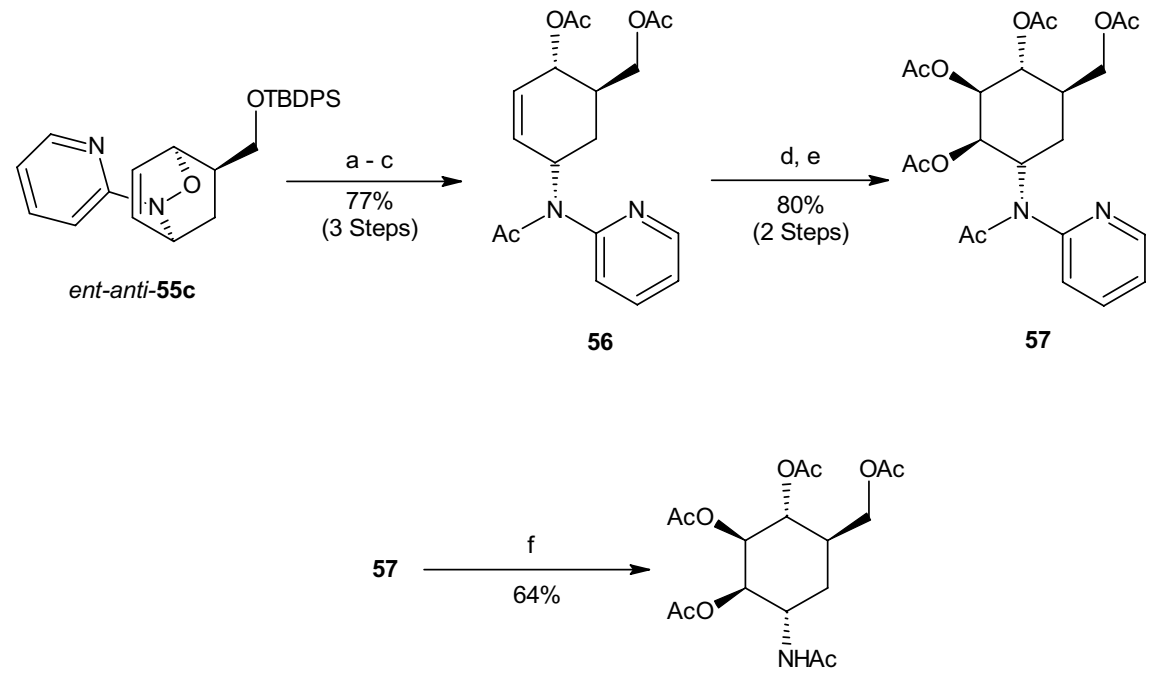

58

Scheme 15 Synthesis of validamine (58). Reagents and conditions: a $\left[\mathrm{Mo}(\mathrm{CO})_{6}\right], \mathrm{NaBH}_{4}, \mathrm{MeOH}_{2} \mathrm{H}_{2} \mathrm{O}$; b TBAF, THF; c $1 . \mathrm{MeMgCl}$, THF, 2. AcCl; d $\mathrm{K}_{2} \mathrm{OsO}_{2}(\mathrm{OH})_{4}, \mathrm{NMO}$, acetone $/ \mathrm{H}_{2} \mathrm{O}$; e $\mathrm{Ac}_{2} \mathrm{O}, \mathrm{C}_{5} \mathrm{H}_{5} \mathrm{~N}$. $T B A F$ tetrabutylammonium fluoride, $N M O$ 4-methylmorpholin-N-oxide; f Rh/C, $\mathrm{H}_{2}$ (70 bar), AcOH, $60{ }^{\circ} \mathrm{C}, 24 \mathrm{~h}(64 \%)$

\subsection{Synthesis Based on lodobenzene}

The next major sources of non-carbohydrate sources for carbasugar synthesis are monosubstituted benzenes. These include regular benzene, methyl benzoate, toluene, and other derivatives of the benzene molecule [43-45]. Here, we outline the various synthetic pathways based on iodobenzene, while reactions based on methyl benzoate are described in the next section.

The research of Boyd et al. [43] precisely describes the synthesis of four 5-(hydroxymethyl)cyclohexane-1,2,3,4-tetraol stereoisomers and their pentaacetylated analogues based on iodobenzene $(1 S, 2 S)$-cis-dihydrodiol 67. By using the $(1 R, 2 R)$-cis-dihydrodiol metabolite of iodobenzene, the same reaction processes yielded four additional stereoisomeric forms [43]. In the following section, we explain the different reactions used to obtain the four carbasugars presented in Scheme 17, carba- $\beta$-D-altropyranose (68), carba- $\alpha$-L-galactopyranose (69), carba- $\beta$ D-idopyranose (70), and carba- $\beta$-L-glucopyranose (71), including their penta-acetate derivatives (not shown) [43].

\subsubsection{Synthesis of Carba- $\beta$-D-Altropyranose and Carba- $\alpha-\mathrm{L}-$ Galactopyranose}

The reaction processes for all four carbasugars are based on iodobenzene cisdihydrodiol 67 (Scheme 18). The synthesis of iodobenzene cis-dihydrodiol from iodobenzene through the use of Pseudomonas putida was clearly reported by Derek et al. [46] and will not be elaborated. The first reaction step involved the 


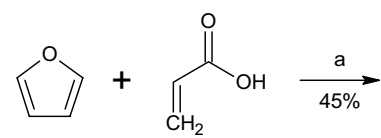<smiles>O=C(O)C1CC2C=CC1O2</smiles>

59

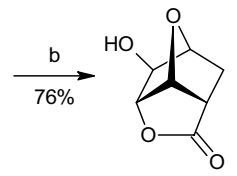

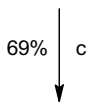<smiles>OC[C@H]1C[C@@H](O)[C@H](O)[C@H](O)[C@@H]1O</smiles>

62<smiles></smiles>

f

63

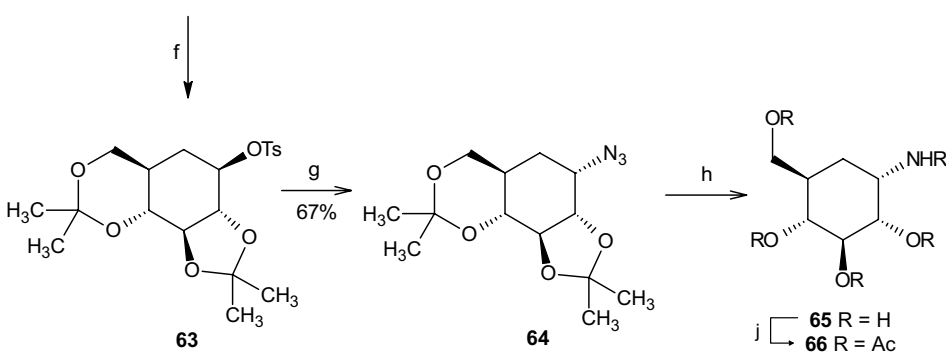<smiles>CC(=O)OC[C@H]1C[C@@H](OC(C)=O)[C@H](OC(C)=O)[C@H](OC(C)=O)[C@@H]1OC(C)=O</smiles>

61<smiles>CC(=O)OC1CC2OC1C(C(C)=O)C2OC(C)=O</smiles>

60

Scheme 16 Synthesis of the racemate corresponding to validamine $\mathbf{6 5}$. Reagents and conditions: a hydroquinone, $\mathrm{N}_{2}, 105 \mathrm{~d}$; b i) ethyl acetate, palladium black, $\mathrm{H}_{2}, 30 \mathrm{~min}$; ii) formic acid $(95 \%), \mathrm{H}_{2} \mathrm{O}_{2}(30 \%)$, $45{ }^{\circ} \mathrm{C}, 5 \mathrm{~min}$; c i) $\mathrm{LiAlH}_{4}$, THF, $\mathrm{H}_{2} \mathrm{O}, 5{ }^{\circ} \mathrm{C}, 15 \mathrm{~min}$; ii) $\mathrm{Ac}_{2} \mathrm{O}, \mathrm{C}_{5} \mathrm{H}_{5} \mathrm{~N}, \mathrm{Al}_{2} \mathrm{O}_{3}, \mathrm{CHCl}_{3}$; d AcOH, $\mathrm{H}_{2} \mathrm{SO}_{4}$, $22 \mathrm{~h}, \mathrm{Ac}_{2} \mathrm{O}$; e MeONa, $70{ }^{\circ} \mathrm{C}, 1 \mathrm{~h}$, Amberlite IR-120(H $\left.{ }^{+}\right)$; f i) 2,2-DMP, DMF, $p$-TSA, $60{ }^{\circ} \mathrm{C}, 3 \mathrm{~h}$; ii) sodium hydrogencarbonate, $p$-TsCl, 2 d; $\mathbf{g ~ N a N}_{3}$, DMF, 2 h; h i) EtOH, Raney $\mathrm{Ni}_{2} \mathrm{H}_{2}, 18$ h; ii) $\mathrm{HCl}$, $80{ }^{\circ} \mathrm{C}, 1 \mathrm{~h}, \mathrm{IRA}-400\left(\mathrm{OH}^{-}\right) ; \mathbf{j} \mathrm{Ac}_{2} \mathrm{O}, \mathrm{C}_{5} \mathrm{H}_{5} \mathrm{~N}, 2 \mathrm{~d}$<smiles>OC[C@H]1C[C@@H](O)[C@H](O)[C@H](O)[C@@H]1O</smiles><smiles>OC[C@H]1C[C@@H](O)[C@H](O)[C@H](O)[C@@H]1O</smiles>

69<smiles>OC[C@H]1C[C@@H](O)[C@H](O)[C@H](O)[C@@H]1O</smiles>

70<smiles>OC[C@H]1C[C@@H](O)[C@H](O)[C@H](O)[C@@H]1O</smiles>

71

Scheme 17 Four carbasugar isomers

addition of a protecting group at the two hydroxyl substituents. This was performed via the addition of 2,2-dimethoxypropane, thereby forming an acetonide protecting group and resulting in a $98 \%$ yield of the $(3 \mathrm{a} S, 7 \mathrm{a} S)$-acetonide derivative 72 (Scheme 18). This step was followed by dihydroxylation through the use of catalytic amounts of osmium tetroxide in acetone and water in the presence of $N$-methylmorpholine $N$-oxide. This process resulted in the $(3 \mathrm{a} S, 4 R, 5 R, 7 \mathrm{a} S)$-diol acetonide isomer $\mathbf{7 3}$ with a yield of $87 \%$. Under a carbon monoxide atmosphere 


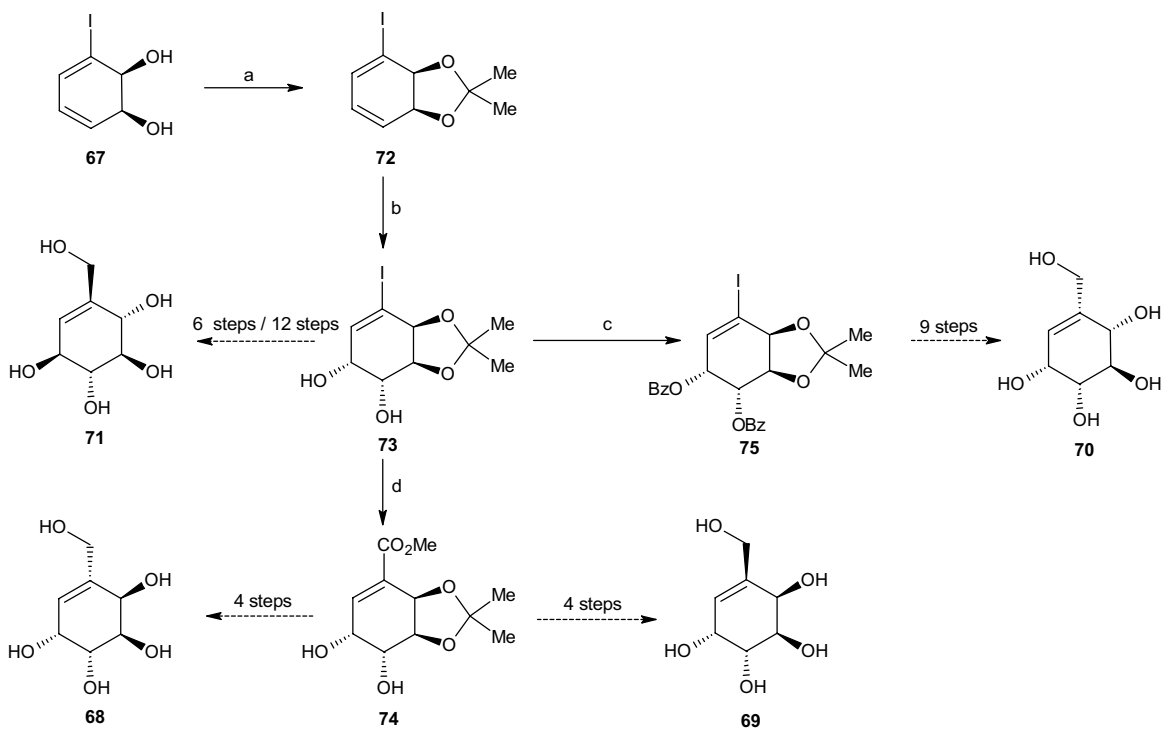

Scheme 18 Synthesis pathways summarized. Reagents and conditions: a 2,2-DMP, $90 \%$ yield, b $\mathrm{OsO}_{4}$, $\mathrm{Me}_{2} \mathrm{CO}, \mathrm{H}_{2} \mathrm{O}, 87 \%$ yield, $\mathbf{c} \mathrm{BzCl}, \mathrm{C}_{5} \mathrm{H}_{5} \mathrm{~N}, 95 \%$ yield, $\mathbf{d} \mathrm{Pd}(\mathrm{OAc})_{2}, \mathrm{CO}, \mathrm{NaOAc}, \mathrm{MeOH}, 81 \%$ yield

with sodium acetate and methanol, the $(3 \mathrm{a} R, 6 R, 7 R, 7 \mathrm{a} S)-\alpha, \beta$-unsaturated ester 74 was created with a yield of $81 \%$ after being catalyzed through palladium(II) acetate [43].

Under a pressure of $55 \mathrm{psi}$, catalytic hydrogenation occurred, resulting in an inseparable mixture consisting of the two epimers $(3 \mathrm{a} R, 4 S, 6 R, 7 R, 7 \mathrm{a} S) \mathbf{7 6}$ and $(3 \mathrm{a} R, 4 R, 6 R, 7 R, 7 \mathrm{a} S) \mathbf{8 0}$ (Scheme 19), with yields of $35 \%$ and $65 \%$, respectively. The next step involved converting both isomers into their dibenzoate derivatives to enable chromatographic separation by preparative thin layer chromatography (PTLC), yielding about $80 \%$ and $86 \%$, respectively (or $28 \%$ and $56 \%$ relative to the catalytic hydrogenation step). After separation of the mixture, the three ester groups of the $(3 \mathrm{a} R, 4 S, 6 R, 7 S, 7 \mathrm{a} R)$-dibenzoate compound $\mathbf{7 7}$ were reduced using LAH, yielding $(3 \mathrm{a} S, 4 R, 5 R, 7 R, 7 \mathrm{a} R)$-acetonide triol 78 (74\%). Using acidcatalyzed deprotection with trifluoroacetic acid, the reactions yielded the desired carba- $\beta$-D-altropyranose $(\mathbf{6 8}, 90 \%)$, which was then purified via charcoal/celite chromatography. The carbasugar was further transformed into its penta-acetate derivative 79 through the use of acetic anhydride and pyridine. The reaction process for carba- $\alpha$-L-galactopyranose (69) occurred under the same conditions.

After separation through PTLC, the other compound $(3 \mathrm{a} R, 4 R, 6 R, 7 S, 7 \mathrm{a} R)$ dibenzoate $\mathbf{8 1}$ was treated with $\mathrm{LAH}$, forming $(3 \mathrm{a} S, 4 R, 5 R, 7 S, 7 \mathrm{a} R)$-acetonide triol 82 in $76 \%$ yield (Scheme 19). Removal of the protecting group, purification, and conversion to the penta-acetate followed the same reaction pathway as that for carba- $\beta$-D-altropyranose, yielding $81 \%$ of carba-L-galactopyranose (69) and $84 \%$ of its penta-acetate derivative $\mathbf{8 3}$ [43]. 


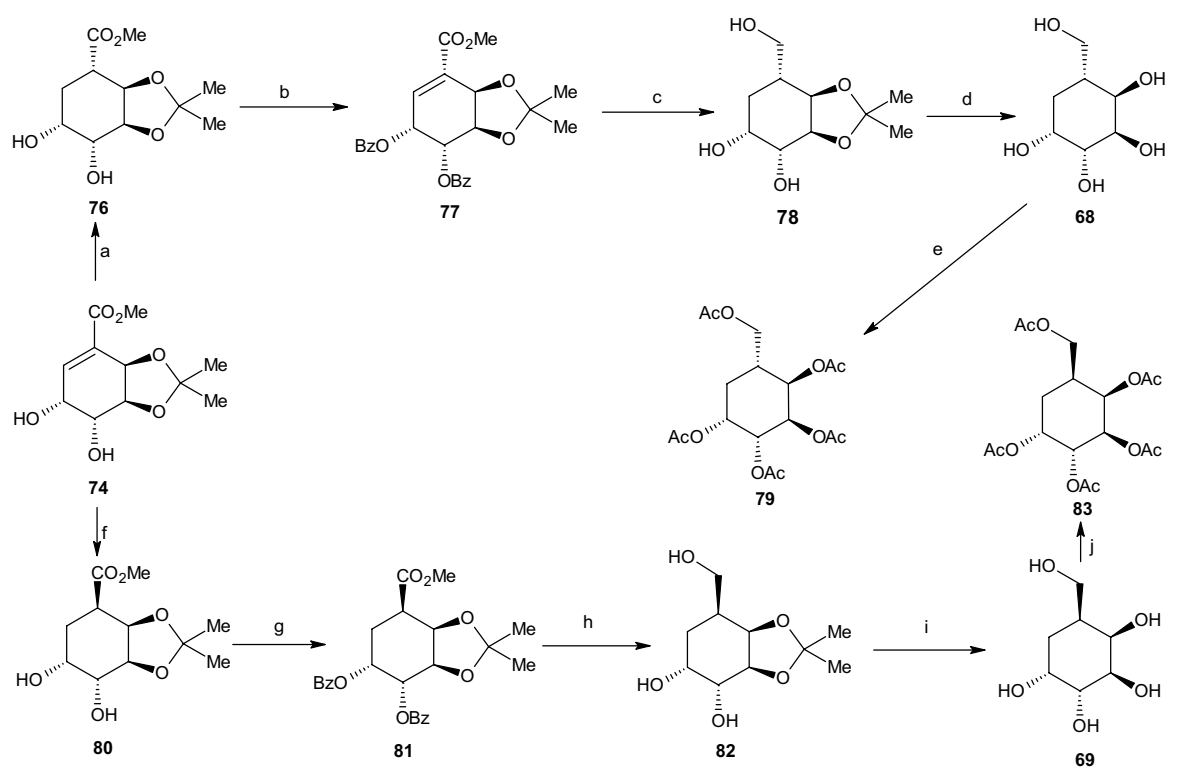

Scheme 19 Synthesis of carba- $\beta$-D-altropyranose (68) and carba- $\alpha$-L-galactopyranose (69). Reagents and conditions: a $\mathrm{H}_{2}, \mathrm{Rh} / \mathrm{Al}_{2} \mathrm{O}_{3}, 35 \%$ yield, b $\mathrm{BzCl}, \mathrm{C}_{5} \mathrm{H}_{5} \mathrm{~N}, 80 \% / 28 \%$ yield, $\mathbf{c} \mathrm{LiAlH}_{4}, 74 \%$ yield, d TFA, $90 \%$ yield, e $\mathrm{Ac}_{2} \mathrm{O}, \mathrm{C}_{5} \mathrm{H}_{5} \mathrm{~N}, 78 \%$ yield, $\mathbf{f} \mathrm{Rh} / \mathrm{AL}_{2} \mathrm{O}_{3}, \mathrm{H}_{2}, 65 \%$ yield, $\mathbf{g ~ B z C l}, \mathrm{C}_{5} \mathrm{H}_{5} \mathrm{~N}, 86 \% / 56 \%$ yield, $\mathbf{h}$ $\mathrm{LiAlH}_{4}, 76 \%$ yield, i TFA, $81 \%$ yield, $\mathbf{j} \mathrm{Ac}_{2} \mathrm{O}, \mathrm{C}_{5} \mathrm{H}_{5} \mathrm{~N}, 84 \%$ yield

\subsubsection{Synthesis of Carba- $\beta$-D-Idopyranose}

The synthesis of carba- $\beta$-D-idopyranose (70) was more challenging. With the synthesis of carba- $\beta$-D-altropyranose (68) and carba- $\alpha$-L-galactopyranose $(69)$, the relative configuration of $\mathrm{C} 2$ and $\mathrm{C} 3$ was identical to those at the iodobenzene dihydrodiol 67. However, with carba- $\beta$-D-idopyranose 70, the relative configuration at $\mathrm{C} 2$ and $\mathrm{C} 3$ was trans, thus requiring inversion at $\mathrm{C} 2$. The reaction began by treating the previously synthesized $(3 \mathrm{a} S, 4 R, 5 R, 7 \mathrm{a} S)$-diol acetonide isomer $\mathbf{7 3}$ with benzoyl chloride and pyridine, giving a 95\% yield of $(3 \mathrm{a} R, 4 S, 5 R, 7 \mathrm{a} S)$-dibenzoate 75 (Scheme 20). This compound was deprotected by hydrochloric acid in methanol, resulting in a $90 \%$ yield of dibenzoate 84. Using triphenylphosphine, diethyl azodicarboxylate (DEAD), and 4-nitrobenzoic acid, with Mitsunobu inversion occurring at the targeted allylic position, the dibenzoate resulted in $(1 R, 4 R, 5 S, 6 S)$ - $p$-nitrobenzoate 85 (70\% yield). By utilization of sodium hydroxide in methanol, esters $\mathrm{R}$ and $\mathrm{R}^{\prime}$ (see Scheme 20) were hydrolyzed, resulting in $(1 R, 2 R, 3 S, 4 R)$-tetraol 86 with a yield of $87 \%$. Subsequently, a protective acetonide group was added through the addition of 2,2-DMP and $p$-toluenesulfonic acid ( $p$-TSA), yielding $89 \%$ of $(3 \mathrm{a} S, 4 R, 5 R, 7 \mathrm{a} R)$ acetonide 87, which was then diacetylated at the two trans hydroxyl groups, forming $(3 \mathrm{a} R, 4 S, 5 R, 7 \mathrm{a} R)$-diacetate $\mathbf{8 8}$ (95\% yield) with $\mathrm{Ac}_{2} \mathrm{O}$ and pyridine. Carbonylation with $\mathrm{CO}$, catalyzed by palladium(II) acetate and sodium acetate in methanol, was used to replace the iodine with a carbomethoxy group, thereby forming the $(3 \mathrm{a} R, 6 S, 7 S, 7 \mathrm{a} R)$-triester 89. Removing the alkene while also ensuring the desired 


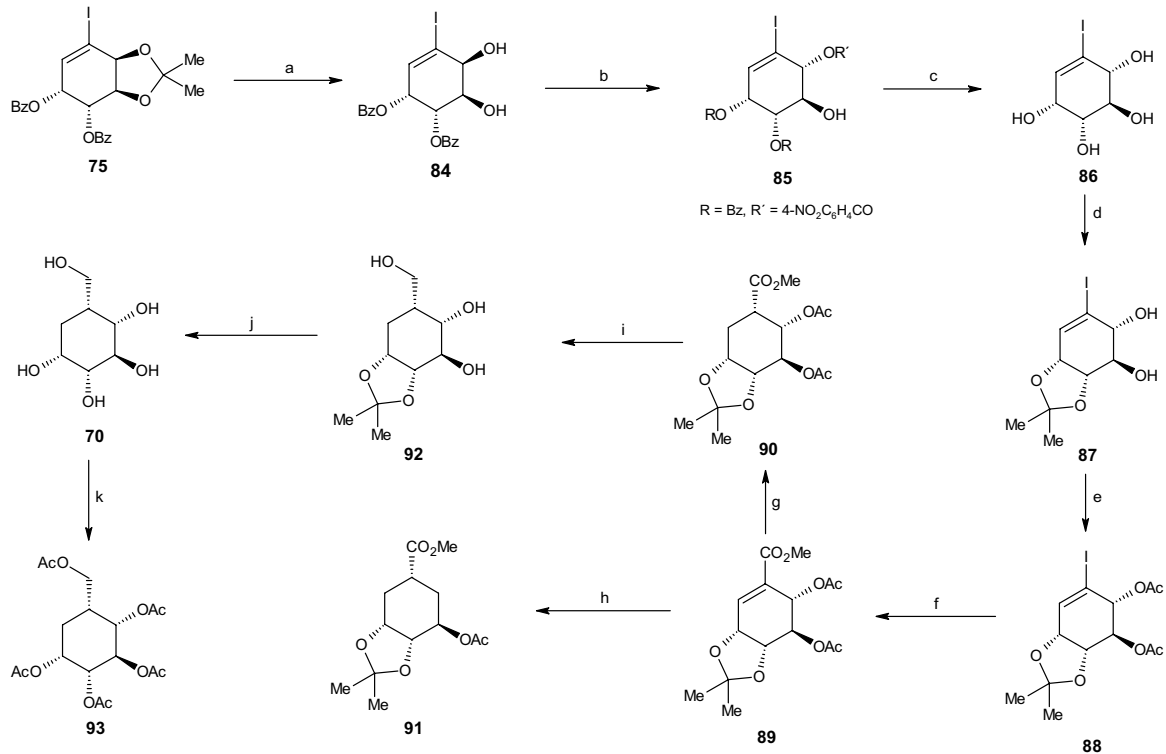

Scheme 20 Synthesis of carba- $\beta$-D-idopyranose. Reagents and conditions: a $\mathrm{HCl}, \mathrm{MeOH}, 90 \%$ yield, b $\mathrm{PPh}_{3}, \mathrm{DEAD}, 4-\mathrm{NO}_{2} \mathrm{C}_{6} \mathrm{H}_{4} \mathrm{CO}_{2} \mathrm{H}, 70 \%$ yield, c $\mathrm{NaOH}, \mathrm{MeOH}, 87 \%$ yield, d 2,2-DMP, p-TSA, 89\% yield, e $\mathrm{Ac}_{2} \mathrm{O}, \mathrm{C}_{5} \mathrm{H}_{5} \mathrm{~N}, 95 \%$ yield, f CO, $\mathrm{Pd}(\mathrm{OAc})_{2}, \mathrm{NaOAc}, \mathrm{MeOH}, 87 \%$ yield, g $\mathrm{Rh} / \mathrm{Al}_{2} \mathrm{O}_{3}, \mathrm{H}_{2}, \mathrm{EtOH}, 40 \%$ yield, h Rh/ $\mathrm{Al}_{2} \mathrm{O}_{3}, \mathrm{H}_{2}$, EtOH, $60 \%$ yield, $\mathbf{i ~ L i A l H}{ }_{4}$, THF, $81 \%$ yield, j $\mathrm{HCl}, \mathrm{MeOH}, 79 \%$ yield, k $\mathrm{Ac}_{2} \mathrm{O}_{3}$, $\mathrm{C}_{5} \mathrm{H}_{5} \mathrm{~N}, 97 \%$ yield

relative configuration via catalytic hydrogenation (similar to Scheme 19) through $\mathrm{Rh} / \mathrm{Al}_{2} \mathrm{O}_{3}$ and $\mathrm{H}_{2}$ in ethanol yielded $40 \%$ of $(3 \mathrm{a} R, 5 \mathrm{~S}, 6 \mathrm{~S}, 7 \mathrm{~S}, 7 \mathrm{a} R)$-triester 90 . However, due to the competing hydrogenolysis, there was also a $60 \%$ yield of an undesired $(3 \mathrm{a} R, 5 S, 7 R, 7 \mathrm{a} R)$-diester 91 (Scheme 20), which was separated easily by chromatography. The reaction continued with triester 90, which was deprotected via the removal of the three ester groups produced by LAH and tetrahydrofuran (THF), giving $(3 \mathrm{a} R, 4 R, 5 S, 6 R, 7 \mathrm{a} R)$-triol $92(81 \%$ yield $)$, followed by the removal of the acetonide group through $\mathrm{HCl}$ in methanol, yielding $79 \%$ of carba- $\beta$-D-idopyranose (70). Similar to both preceding reactions, the carbasugar was transformed into its pentaacetate derivative 93, again through the use of $\mathrm{Ac}_{2} \mathrm{O}$ and pyridine, with a yield of $97 \%$ [43].

\subsubsection{Synthesis of Carba-a-L-Glucopyranose}

The reaction pathway for the final carbasugar carba- $\alpha$-L-glucopyranose (71) started with $(3 \mathrm{a} S, 4 R, 5 R, 7 \mathrm{a} S)$-diol acetonide isomer 73, synthesized under the carba-bD-altropyranose pathway (Scheme 18). Again, the trans-configuration at C2 and C3 differed from that of iodobenzene cis-dihydrodiol 67, as well as that at $\mathrm{C} 4$ and $\mathrm{C} 5$, requiring inversion at $\mathrm{C} 2$ and $\mathrm{C} 5$. The reaction started by deprotecting compound $\mathbf{7 3}$ using $\mathrm{HCl}$ in methanol (Scheme 21), yielding $85 \%$ of $(1 R, 2 R, 3 S, 4 S)$-anti-tetraol 94, followed by treatment with 1-bromocarbonyl-1-methylethyl acetate, which produced 


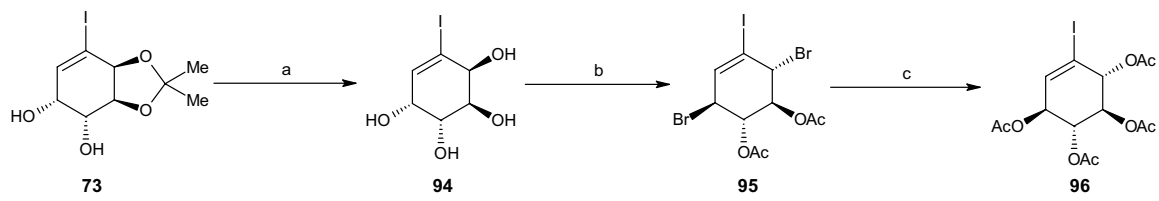

96
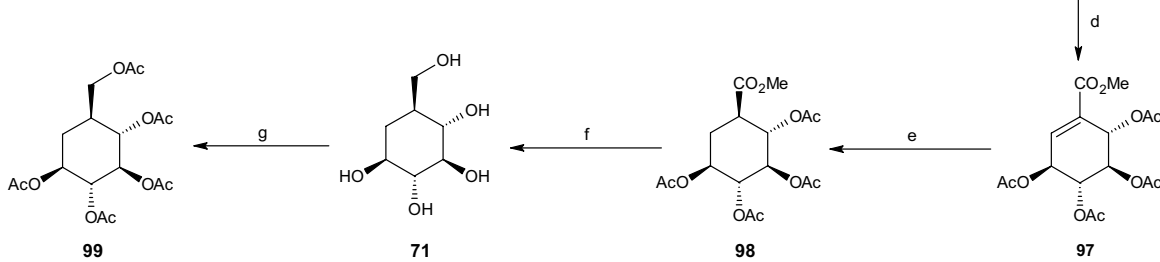

Scheme 21 Synthesis of carba- $\beta$-L-glucopyranose. Reagents and conditions: a HCl/MeOH, $85 \%$ yield, b $\mathrm{AcOCMe}_{2} \mathrm{COBr}, 87 \%$ yield, c $\mathrm{AgOAc} / \mathrm{AcOH} / \mathrm{Ac} 2 \mathrm{O}, 77 \%$ yield, d $\mathrm{Pd}(\mathrm{OAc})_{2}, \mathrm{CO}, \mathrm{NaOAc}, \mathrm{THF}, \mathrm{H}_{2} \mathrm{O}$, $73 \%$ yield, e $\mathrm{Rh} / \mathrm{Al}_{2} \mathrm{O}_{3}, \mathrm{H} 2,80 \%$ yield, $\mathbf{f} \mathrm{LiAlH}_{4}, 12 \%$ yield, $\mathbf{g} \mathrm{Ac}_{2} \mathrm{O}, 95 \%$ yield

the desired inversion at $\mathrm{C} 2$ and $\mathrm{C} 5$ and yielded $87 \%$ of (1S,2R,5S,6S)-dibromo diacetoxy derivative 95. Utilizing Woodward-Winstein conditions [47], silver acetate, acetic acid, and $\mathrm{Ac}_{2} \mathrm{O}$ yielded $77 \%(1 R, 2 S, 5 R, 6 S)$-tetra-acetate 96, preserving all four desired chiral configurations. The addition of palladium(II) acetate, $\mathrm{NaOAc}$, THF, and water under a carbon monoxide atmosphere was performed to replace the iodine with a carbomethoxy group, yielding $73 \%$ of unsaturated $(3 S, 4 R, 5 R, 6 S)$ tetra-acetate 97, followed by catalytic hydrogenation, which resulted in saturated $(1 R, 2 S, 3 R, 4 R, 5 S)$-tetra-acetate $\mathbf{9 8}$ with a yield of $80 \%$ under similar conditions to those employed in earlier synthesis pathways, using $\mathrm{Rh} / \mathrm{Al}_{2} \mathrm{O}_{3}$ and $\mathrm{H}_{2}$. Reducing the tetra-acetate with LAH yielded $12 \%$ of carba- $\alpha$-L-glucopyranose (71). Due to this surprisingly low yield, another synthesis pathway using a higher step count was developed. Similar to all three other carbasugars, $(1 S, 2 S, 3 R, 4 R, 5 S)$-penta-acetate 99 was formed under the same conditions, yielding 95\% (Scheme 21) [43].

\subsubsection{Alternate Synthesis of Carba- $\beta-\mathrm{L}-$ Glucopyranose}

As noted earlier, the previously presented synthesis pathway for carba- $\beta$-Lglucopyranose did not yield a suitable amount of the desired carbasugar. Thus, a longer yet more efficient synthesis pathway was developed.

The reaction started with the same reactant used in 2.4.3: (3aS,4R,5R,7aS)-cis-diol acetonide 73. Utilizing Mitsunobu inversion conditions similar to those presented in Scheme 20, inversion occurred at C5, yielding $80 \%(3 \mathrm{a} S, 4 S, 5 S, 7 \mathrm{a} S)$ 4-nitrobenzoate 100 (Scheme 22). Through the use of potassium carbonate in methanol, the nitro benzoate compound $\mathbf{1 0 0}$ was transformed into $(3 \mathrm{a} S, 4 R, 5 S, 7 \mathrm{a} S)$-trans-diol acetonide 101 ( $82 \%$ yield), in which the two trans hydroxyl groups were protected by the benzoyl groups, yielding $93 \%$ ( $3 \mathrm{a} S, 4 S, 5 R, 7 \mathrm{a} S)$-trans-dibenzoate acetonide $\mathbf{1 0 2}$. An acidcatalyzed reaction led to removal of the acetonide group from compound 102, forming $(1 S, 4 S, 5 R, 6 S)$-cis-diol dibenzoate $\mathbf{1 0 3}$ with a yield of $86 \%$. A second Mitsunobu reaction was then required to achieve the final relative configuration of all five carbon atoms. This occurred under the same conditions reported previously, resulting in 


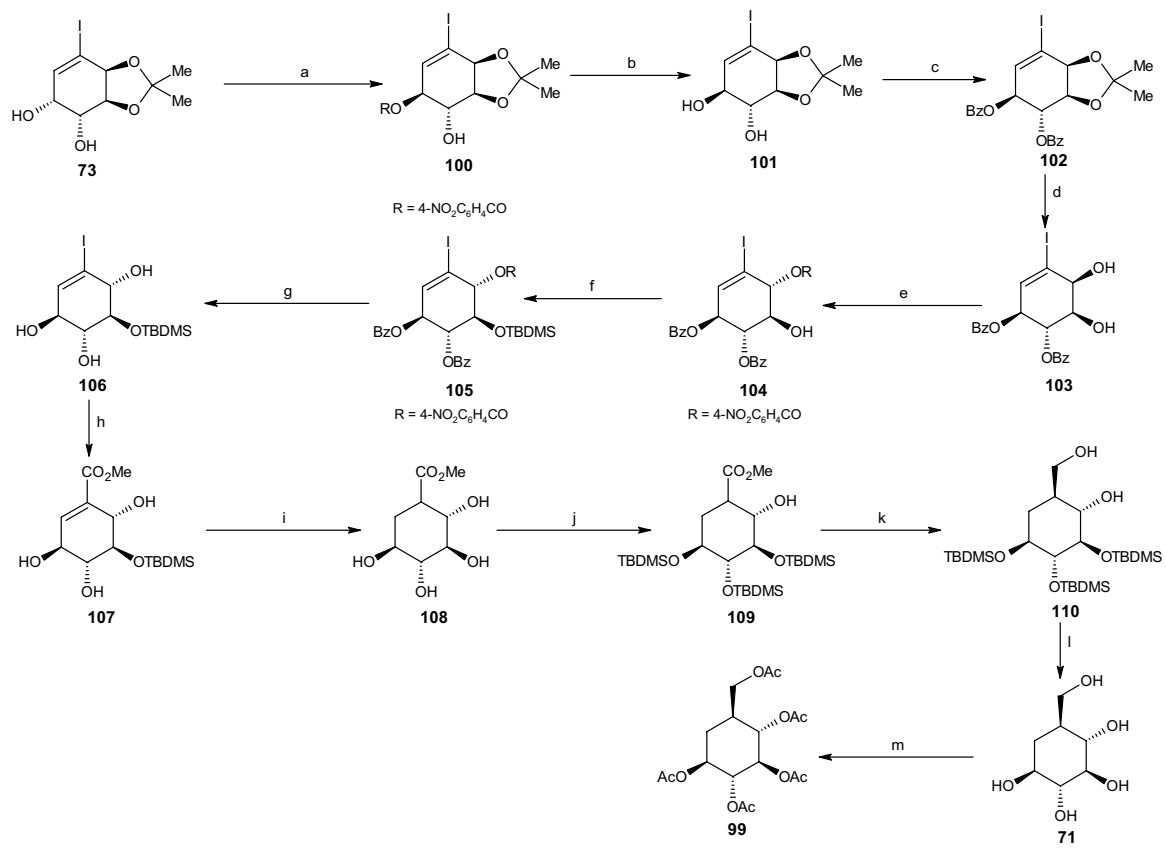

Scheme 22 Alternate synthesis of carba- $\beta$-L-glucopyranose. Reagents and conditions: a $\mathrm{PPh}_{3}, \mathrm{DEAD}$, 4- $\mathrm{NO}_{2} \mathrm{C}_{6} \mathrm{H}_{4} \mathrm{CO}_{2} \mathrm{H}, 80 \%$ yield, $\mathbf{b} \mathrm{K}_{2} \mathrm{CO}_{3}, \mathrm{MeOH}, 82 \%$ yield, $\mathbf{c} \mathrm{BzCl}, \mathrm{C}_{5} \mathrm{H}_{5} \mathrm{~N}, 93 \%$ yield, d $\mathrm{HCl}, \mathrm{MeOH}$, $86 \%$ yield, e $\mathrm{PPh}_{3}, \mathrm{DEAD}, 4-\mathrm{NO}_{2} \mathrm{C}_{6} \mathrm{H}_{4} \mathrm{CO}_{2} \mathrm{H}, 80 \%$ yield, $\mathbf{f}$ TBDMSOTf, 93\% yield, $\mathbf{g} \mathrm{NaOH}, \mathrm{MeOH}$, $82 \%$ yield, h CO, $\mathrm{Pd}(\mathrm{OAc})_{2}, \mathrm{NaOAc}$, THF, $\mathrm{H}_{2} \mathrm{O}, 69 \%$ yield, $\mathbf{i} \mathrm{Rh} / \mathrm{Al}_{2} \mathrm{O}_{3}, \mathrm{H}_{2}, 80 \%$ yield, $\mathbf{j}$ TBDMSOTf, $95 \%$ yield, $\mathbf{k} \mathrm{LiAlH}_{4}, 82 \%$ yield, $\mathbf{I}$ TBAF, THF, $78 \%$ yield, $\mathbf{m ~ A c} \mathrm{Ac}_{2} \mathrm{C}_{5} \mathrm{H}_{5} \mathrm{~N}, 97 \%$ yield

inversion at $\mathrm{C} 2$ and yielding $80 \%$ of the $(1 R, 4 S, 5 S, 6 S)$-triester compound 104. The hydroxyl group at $\mathrm{C} 3$ was protected by the addition of trifluoromethanesulfonic acid tert-butyldimethylsilyl ester (TBDMSOTf), giving a 93\% yield of $(1 R, 4 S, 5 R, 6 S)$ TBDMS ether 105, followed by deprotection of the three remaining hydroxyl groups using $\mathrm{NaOH}$ in methanol, thereby yielding $86 \%$ of $(1 S, 2 R, 3 S, 4 R)$-triol 106 (Scheme 22). The next step involved substitution of the iodine with a carbomethoxy group using similar conditions to those employed in previous schemes, thus forming an unsaturated $(3 S, 4 R, 5 R, 6 S)$-ester 107 with a yield of $69 \%$. This ester compound was hydrogenated into the saturated $(1 R, 2 S, 3 R, 4 R, 5 S)$-ester 108 with a yield of $80 \%$ and trans configuration between the carbomethoxy and adjacent hydroxyl group. Through the addition of TBDMSOTf, $(1 S, 2 S, 3 R, 4 R, 5 S)$-tri-TBDMS ester 109 was achieved. Similar to previously described schemes, the addition of LAH resulted in reduction of the carbomethoxy group to a hydroxyl methyl group, yielding compound $(1 S, 2 R, 3 R, 4 S, 5 S)$-tri-TBDMS ether 110.

Deprotection in $\mathrm{HCl}$ and methanol using tetra- $n$-butylammonium fluoride (TBAF) and THF resulted in a 78\% yield of the desired carba- $\beta$-L-glucopyranose (71). As with all previous reactions, the carbasugar was purified using charcoal/ Celite and further characterized as its penta-acetate derivative 99 (Scheme 22) [43]. 


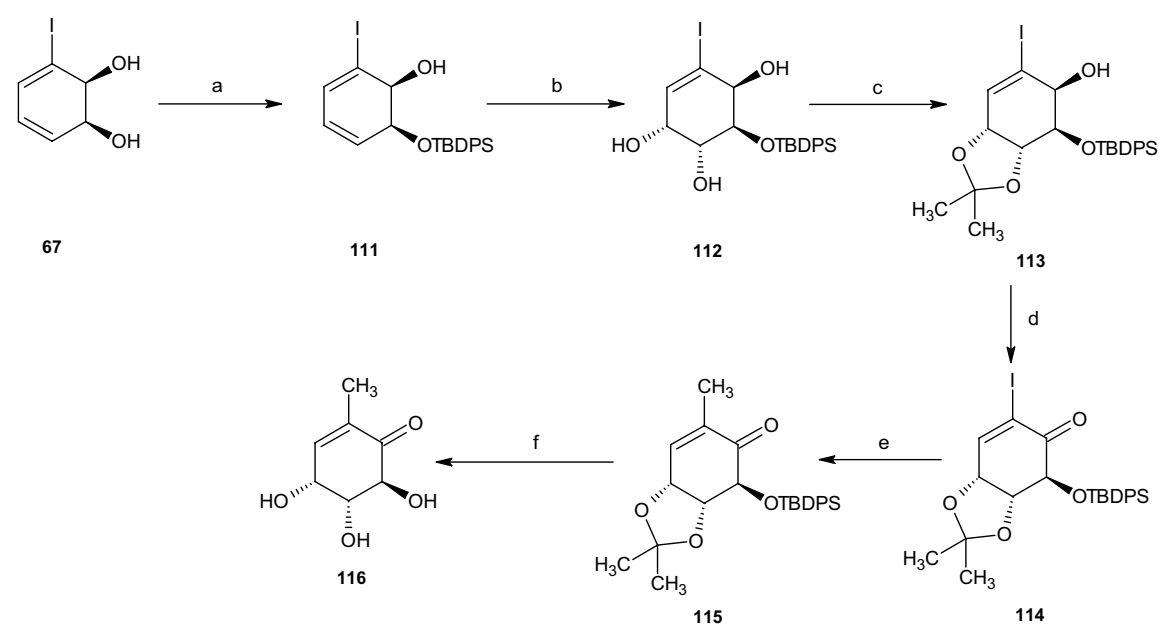

Scheme 23 Synthesis of (-)-gabosine A (116). Reagents and conditions: a TBDPSCl, imidazole, $\mathrm{CH}_{2} \mathrm{Cl}_{2}$, b OsO $\mathrm{O}_{4}, \mathrm{NMO}$, acetone- $\mathrm{H}_{2} \mathrm{O}$, c 2,2-DMP, $p$-TSA, $\mathrm{Et}_{3} \mathrm{~N}, \mathbf{d} \mathrm{COCl}_{2}, \mathrm{DMSO}, \mathrm{Et}_{3} \mathrm{~N}, \mathbf{e} \mathrm{MeMgCl}$, $\mathrm{FeCl}_{3}, \mathrm{NMP}, \mathrm{THF}, \mathbf{f ~ H C l}, \mathrm{MeOH},\left(\mathrm{Me}_{2} \mathrm{~N}_{3} \mathrm{~S}^{+} \mathrm{F}_{2} \mathrm{SiMe}_{3}{ }^{-}\right.$, THF

\subsubsection{Synthesis of (-)-Gabosine A}

Based on iodobenzene (1S,2S)-cis-dihydrodiol 67, Banwell et al. [48] presented a pathway that provides (-)-gabosine A (116) over six steps (Scheme 23). The reaction started by protecting compound 67 at the less sterically hindered hydroxyl group at $\mathrm{C} 1$ under a nitrogen atmosphere, thus forming TBDPS-ether 111. Utilizing UpJohn dihydroxylation conditions [49], two hydroxyl groups were formed at the non-halogenated carbon-carbon double bond, yielding triol 112. The addition of an acetonide occurred under known conditions in the presence of triethylamine, thereby forming acetonide compound 113. This compound was oxidized under Swern conditions, yielding the ketone 114, followed by replacement of the iodine with a methyl group, utilizing iron-catalyzed reactions developed by Cahiez and Avedissian [50].

Deprotection under acidic conditions and THF gave a 1:2 mixture of (-)-gabosine A (116) and its 6-TBDPS ether derivative, which was then treated with THF and tris(dimethylamino)sulfonium difluorotrimethylsilicate (TASF), to remove the silyl ether group and form the desired (-)-gabosine A (116, Scheme 23) [48].

\subsection{Synthesis Based on Methyl Benzoate}

As stated in the previous section, various different types of benzene derivatives are used for carbasugar synthesis. This section explores methyl benzoate as a reactant. Similarly, methyl benzoate was converted into its cis-dihydrodiol metabolite, thereby ensuring the same skeletal structure as mono carbasugars along with the desired relative configuration at $\mathrm{C} 2$ and $\mathrm{C} 3$ to synthesize three more sugar analogues.

The work of Boyd et al. explored the synthesis of three more carbasugars, carba- $\beta$ L-galactopyranose (117), carba- $\beta$-L-talopyranose (118), and carba- $\alpha$-L-talopyranose 
<smiles>OC[C@H]1C[C@@H](O)[C@H](O)[C@H](O)[C@@H]1O</smiles>

117<smiles>OC[C@H]1C[C@@H](O)[C@H](O)[C@H](O)[C@@H]1O</smiles>

118<smiles>OC[C@H]1C[C@@H](O)[C@H](O)[C@H](O)[C@@H]1O</smiles>

119

Scheme 24 Three carbasugar isomers<smiles>CC(=O)OC1=CC=C[C@H](O)[C@@H]1O</smiles>

120<smiles>OC[C@H]1C[C@@H](O)[C@H](O)[C@H](O)[C@@H]1O</smiles>

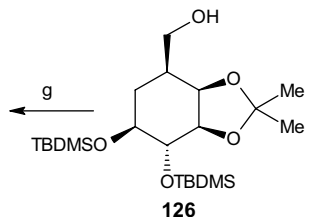

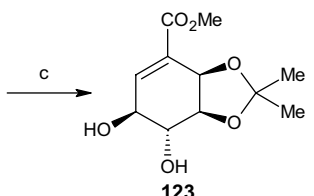

122

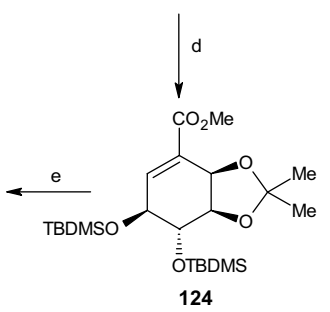

Scheme 25 Synthesis of carba- $\beta$-L-galactopyranose. Reagents and conditions: a 2,2-DMP, $p$-TSA, $93 \%$ yield, b MCPBA, $\mathrm{CH}_{2} \mathrm{Cl}_{2}, 77 \%$ yield, c ${ }^{t} \mathrm{BuOH}, \mathrm{H}_{2} \mathrm{O}$, pH 8 buffer, $70 \%$ yield, d TBDMSOTf, Et ${ }_{3} \mathrm{~N}$, $\mathrm{CH}_{2} \mathrm{Cl}_{2}, 82 \%$ yield, e $\mathrm{Rh} / \mathrm{Al}_{2} \mathrm{O}_{3}, \mathrm{H}_{2}, \mathrm{EtOH}, 62 \%$ yield, f $\mathrm{LiAlH}_{4}, \mathrm{Et}_{2} \mathrm{O}, 84 \%$ yield, $\mathbf{g ~ M e O H}, \mathrm{HCl}, 84 \%$ yield

(119, Scheme 24), based on the same starting material presented in the previous paragraph, iodobenzene cis-dihydrodiol $\mathbf{6 7}$, which was carbonylated using palladium(II) acetate and $\mathrm{NaOAc} \cdot 3 \mathrm{H}_{2} \mathrm{O}$ in methanol under a carbon monoxide atmosphere to yield the $(1 S, 2 R)$-cis-dihydrodiol derivative $\mathbf{1 2 0}$ of methyl benzoate [51]. This cis-dihydrodiol was the starting point for all three synthesis pathways.

\subsubsection{Synthesis of Carba- $\beta$-L-Galactopyranose}

The synthesis started by protecting the previously created cis-dihydrodiol derivative 120 with DMP and p-TSA, yielding 93\% of the acetonide compound 121 (see Scheme 25). Epoxidation occured at C5 and C6 via epoxidation using meta-chloroperoxybenzoic acid (MCPBA) in dichloromethane to yield epoxide $\mathbf{1 2 2}$ (77\% yield). Using tert-butanol in water with a $\mathrm{pH} 8$ buffer led to ring opening at the epoxide, yielding $70 \%$ of trans-dihydrodiol $\mathbf{1 2 3}$. This compound was protected by tertbutyldimethylsilyl trifluoromethanesulfonate (TBDMSOTf) at C4 and C5 to give the di-TBDMS derivative $\mathbf{1 2 4}$ and hydrogenation similar to the previous reactions 


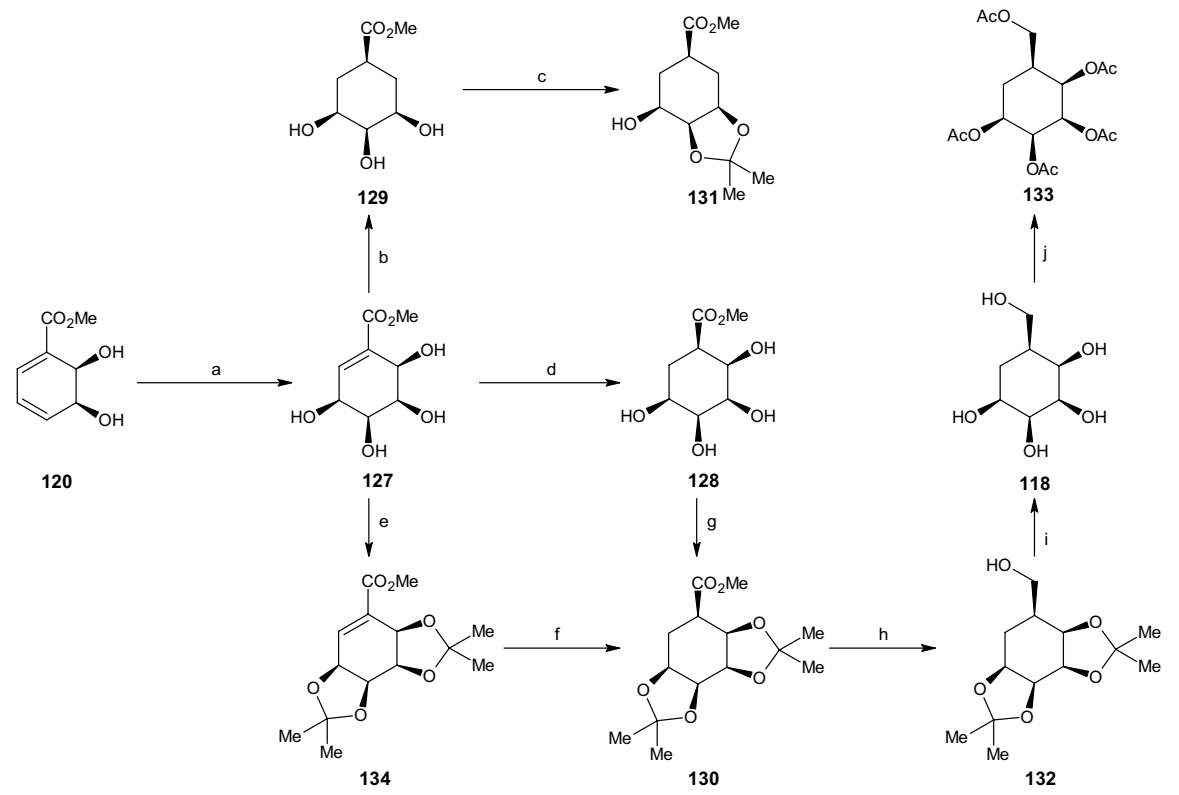

Scheme 26 Synthesis of carba- $\beta$-L-talopyranose. Reagents and conditions: a OsO $70 \%$ yield, b $\mathrm{Rh} / \mathrm{Al}_{2} \mathrm{O}_{3}, \mathrm{H}_{2}$, EtOH, $30 \%$ yield, c 2,2-DMP, $p$-TSA, $25 \%$ yield, d $\mathrm{Rh} / \mathrm{Al}_{2} \mathrm{O}_{3}, \mathrm{H}_{2}$, EtOH, $70 \%$ yield, e 2,2-DMP, $p$-TSA, $80 \%$ yield, $\mathbf{f ~} \mathrm{Rh} / \mathrm{Al}_{2} \mathrm{O}_{3}, \mathrm{H}_{2}$, EtOH, $91 \%$ yield, g 2,2-DMP, $p$-TSA, 59\% yield, h $\mathrm{LiAlH}_{4}, \mathrm{Et}_{2} \mathrm{O}, 76 \%$ yield, i TFA, THF, $\mathrm{H}_{2} \mathrm{O}, 86 \%$ yield, $\mathbf{j} \mathrm{Ac}_{2} \mathrm{O}, \mathrm{C}_{5} \mathrm{H}_{5} \mathrm{~N}, 85 \%$ yield

catalyzed by $\mathrm{Rh} / \mathrm{Al}_{2} \mathrm{O}_{3}$ yielded $82 \%$ of the saturated compound 125 . This was followed by treatment with $\mathrm{LAH}$ in $\mathrm{Et}_{2} \mathrm{O}$, resulting in $84 \%$ of the protected carba- $\beta$ - $\mathrm{L}-$ galactopyranose 126. The compound was deprotected under acidic conditions, yielding $84 \%$ of carba- $\beta$-L-galactopyranose (117) [51].

\subsubsection{Synthesis of Carba- $\beta$-L-Talopyranose}

The next reactions started with the previously synthesized cis-dihydrodiol methyl benzoate derivative 120 (Scheme 26). The addition of osmium tetroxide with trimethylamine- $N$-oxide in a dichloromethane solution resulted in a $70 \%$ yield of the tetraol compound 127. Catalytic hydrogenation resulted primarily in the saturated tetraol compound 128, while also yielding 30\% of the achiral meso-triol 129. This mixture was inseparable under charcoal/Celite chromatography and was treated with 2,2-DMP and p-TSA, resulting in a mono acetonide 131/bis-acetonide 130 mixture, which was then separated using flash-column chromatography to yield $59 \%$ of the bis-acetonide compound $\mathbf{1 3 0}$.

An alternative synthesis route was also explored. This route began with compound 127 and results in the same saturated bis-acetonide compound 130. This synthesis was achieved by changing the order of the two reactions (hydrogenation and protecting). This process started by protecting all four hydroxyl groups with an acetonide using 2,2-DMP and p-TSA to yield $80 \%$ of another bis-acetonide compound 


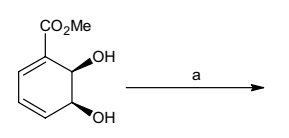

120

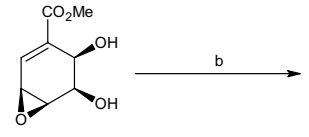

135

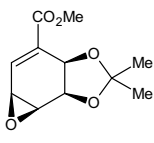

136

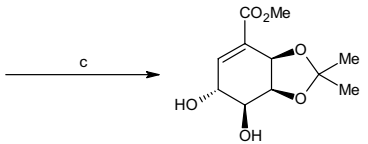

137

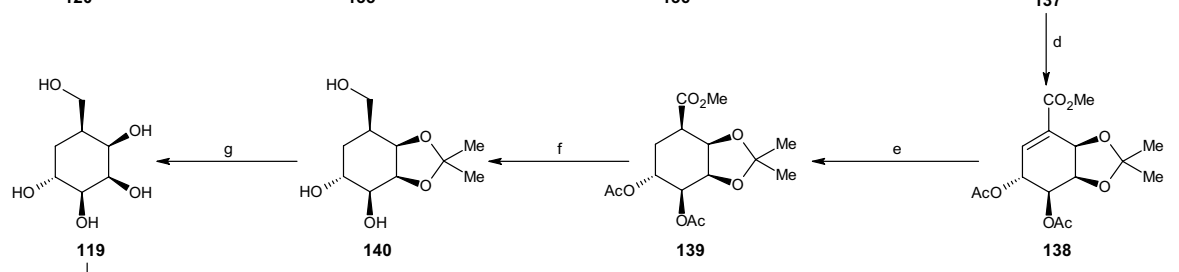

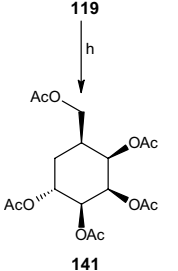

Scheme 27 Synthesis of carba- $\alpha$-L-talopyranose. Reagents and conditions: a MCPBA, $\mathrm{CH}_{2} \mathrm{Cl}_{2}, 82 \%$ yield, b 2,2-DMP, $p$-TSA, 98\% yield, c t- $\mathrm{BuOH}, \mathrm{H}_{2} \mathrm{O}$, pH 8 buffer, $68 \%$ yield, d $\mathrm{Ac}_{2} \mathrm{O}, \mathrm{C}_{5} \mathrm{H}_{5} \mathrm{~N}, 98 \%$ yield, e $\mathrm{Rh} / \mathrm{Al}_{2} \mathrm{O}_{3}, \mathrm{H}_{2}$, EtOH, $83 \%$ yield, $\mathbf{f} \mathrm{LiAlH}_{4}, \mathrm{Et}_{2} \mathrm{O}, 71 \%$ yield, $\mathbf{g}$ TFA, THF, $\mathrm{H}_{2} \mathrm{O}, 88 \%$ yield, $\mathbf{h}$ $\mathrm{Ac}_{2} \mathrm{O}, \mathrm{C}_{5} \mathrm{H}_{5} \mathrm{~N}, 82 \%$ yield

134 and was followed by catalytic hydrogenation utilizing the previously presented conditions. This process afforded $91 \%$ of the desired saturated bis-acetonide while completely suppressing the competing hydrogenation reaction (i.e., $\mathbf{1 2 7} \rightarrow \mathbf{1 2 8} / \mathbf{1 2 9}$ ). Both remaining steps were similar to all previous reactions, starting with reduction of the carbomethoxy group function to a hydroxymethyl group (Scheme 26) using $\mathrm{LAH}$ in $\mathrm{Et}_{2} \mathrm{O}$ to give alcohol compound 132 (76\% yield) and deprotection using TFA in aqueous THF to yield $86 \%$ of carba- $\beta$-L-talopyranose (118). The carbasugar was then converted to its penta-acetate derivative 133 using $\mathrm{A}_{\mathrm{c} 2} \mathrm{O}$ and pyridine $(85 \%$ yield) for characterization [51].

\subsubsection{Synthesis of Carba-a-L-Talopyranose}

Finally, carba- $\alpha$-L-talopyranose (119) was synthesized in seven steps (Scheme 27). The reaction started with the installation of an epoxide group at C4 and C5 of the cis-dihydrodiol derivative of methyl benzoate 120. This was achieved via the addition of MCPBA in dichloromethane to give $82 \%$ cis-diol epoxide $\mathbf{1 3 5}$. Compound 135 was protected by an acetonide ( $98 \%$ yield), followed by opening the epoxide ring using tert-butanol in water ( $\mathrm{pH} 8$ buffer) to produce $68 \%$ of cyclohexene transdiol 137. The two hydroxyl groups were then protected by acetylation, yielding 98\% triester 138. Through catalytic hydrogenation similar to previous reactions, compound 138 was transformed into the saturated ester 139 (83\% yield). LAH was added to a $\mathrm{Et}_{2} \mathrm{O}$ solution to afford the trihydroxy acetonide-protected carba- $\alpha$-Ltalopyranose (140, 71\% yield). The compound was deprotected using TFA and THF in water, yielding $88 \%$ of the desired carbasugar 119. Furthermore, the compound 


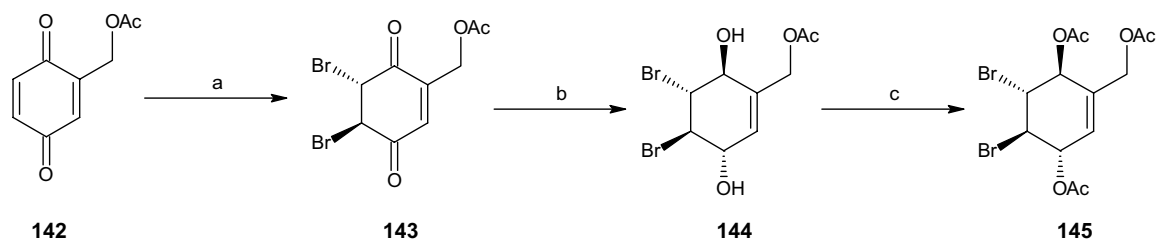

Scheme 28 Synthesis of racemic intermediate 145. Reagents and conditions: a $\mathrm{Br}_{2}, \mathrm{CH}_{2} \mathrm{Cl}_{2}, 98 \%$ yield, b $\mathrm{NaBH}_{4}, \mathrm{Et}_{2} \mathrm{O} / \mathrm{H}_{2} \mathrm{O}, 82 \%$ yield, c $\mathrm{Ac}_{2} \mathrm{O}, \mathrm{C}_{5} \mathrm{H}_{5} \mathrm{~N}, 51 \%$ yield<smiles>CC1=CC(=O)C=CC1=O</smiles>

Scheme 29 Synthesis of racemic intermediate 149. Reagents and conditions: $\mathbf{a} \mathrm{Br}_{2}, \mathrm{CH}_{2} \mathrm{Cl}_{2}, 96 \%$ yield, b $\mathrm{NaBH}_{4}, \mathrm{Et}_{2} \mathrm{O} / \mathrm{H}_{2} \mathrm{O}, 91 \%$ yield, c $\mathrm{Ac}_{2} \mathrm{O}, \mathrm{C}_{5} \mathrm{H}_{5} \mathrm{~N}, 60 \%$ yield

was transformed into its penta-acetate derivative under the same conditions, with a yield of $82 \%$ (141) [51].

\subsection{Based on Benzoquinone}

The final section covers the synthetic pathways for various unsaturated carbasugars, including streptol and gabosine, resulting from masked p-benzoquinone. Leermann et al. [16] explored the synthesis of several unsaturated carbasugars used in lectinbinding studies to determine the influence of sugar derivatives on enzyme inhibition and cancer therapy.

\subsubsection{Synthesis of Dibromo Acetate Intermediates}

The starting materials for all pathways in this section were the two intermediates 145 and 149 formed from 2-acetoxymethyl benzoquinone (142) and 2-methyl benzoquinone (146), respectively (Schemes 28, 29). 2-Acetoxymethyl benzoquinone (142) was dibrominated regioselectively at the unsubstituted double bond, yielding $98 \%$ of dibromo acetate $\mathbf{1 4 3}$. This compound was further reduced using sodium borohydride in diethyl ether and water ( $82 \%$ yield) and acetylated under the conditions described in previous sections to form the racemic dibromo acetoxymethyl diacetate intermediate 145 [16].

Under equal reaction conditions, 2-methyl benzoquinone (146) was transformed into the dibromo compound 147 ( $96 \%$ yield) and reduced to generate $91 \%$ of compound 148. This compound was acetylated to form the dibromo methyl diacetate intermediate 149 with a $60 \%$ yield (Scheme 29) [16]. 


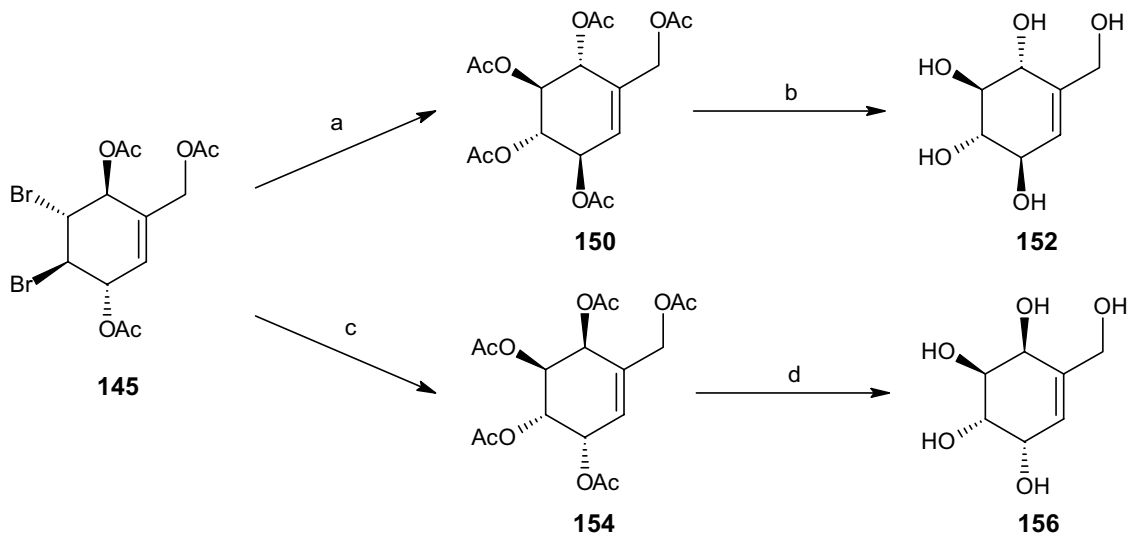

Scheme 30 Synthesis of racemic diastereoisomers 152 and 156. Reagents and conditions: a AgOAc, $\mathrm{AcOH}, \mathrm{Ac}_{2} \mathrm{O}, 71 \%$ yield, b $\mathrm{NaOMe}, \mathrm{MeOH}, 100 \%$ yield, c $\mathrm{AgOAc}, 90 \% \mathrm{AcOH}, \mathrm{Ac}_{2} \mathrm{O}, \mathrm{C}_{5} \mathrm{H}_{5} \mathrm{~N}, 35 \%$ yield, $\mathbf{d} \mathrm{NaOMe}, \mathrm{MeOH}, 82 \%$ yield<smiles>CC(=O)O[C@H]1C=C(C)[C@@H](OC(C)=O)[C@H](Br)[C@@H]1Br</smiles>

149
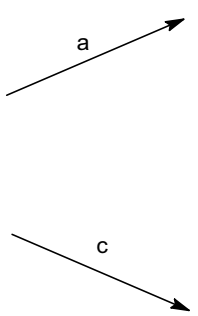<smiles>CC(=O)O[C@H]1[C@H](OC(C)=O)C(C)=C[C@@H](OC(C)=O)[C@H]1OC(C)=O</smiles>

151<smiles>CC(=O)O[C@H]1C=C(C)[C@@H](OC(C)=O)[C@H](OC(C)=O)[C@@H]1OC(C)=O</smiles>

155<smiles>CC1=C[C@H](O)[C@H](O)[C@H](O)[C@@H]1O</smiles>

153<smiles>CC1=C[C@H](O)[C@H](O)[C@H](O)[C@@H]1O</smiles>

Scheme 31 Synthesis of racemic diastereoisomers 153 and 157. Reagents and conditions: a AgOAc, $\mathrm{AcOH}, \mathrm{Ac}_{2} \mathrm{O}, 67 \%$ yield, b $\mathrm{NaOMe}, \mathrm{MeOH}, 88 \%$ yield, c $\mathrm{AgOAc}, 90 \% \mathrm{AcOH}, \mathrm{Ac}_{2} \mathrm{O}, \mathrm{C}_{5} \mathrm{H}_{5} \mathrm{~N}, 32 \%$ yield, d $\mathrm{NaOMe}, \mathrm{MeOH}, 88 \%$ yield

\subsubsection{Synthesis of Unsaturated Penta- and Tetraols}

By utilizing Prévost conditions [52], silver acetate, acetic acid, and acetic anhydride, the dibromo acetoxymethyl diacetate intermediate 145 was transformed into pentaacetate $\mathbf{1 5 0}$ in $\mathbf{7 1 \%}$ yield (Scheme 30). The entire yield of compound $\mathbf{1 5 0}$ was deacetylated via sodium methoxide in methanol, forming pentaol 152. Similarly, the intermediate compound 149 was acetylated to give the tetra acetate 151 (67\% yield) and deprotected to afford unsaturated rac-tetraol 153 (88\% yield, Scheme 31) [16].

The penta-acetate 154 and tetra acetate 155 were obtained from intermediates 145 and 149, respectively, through the use of Woodward conditions [50] (silver 


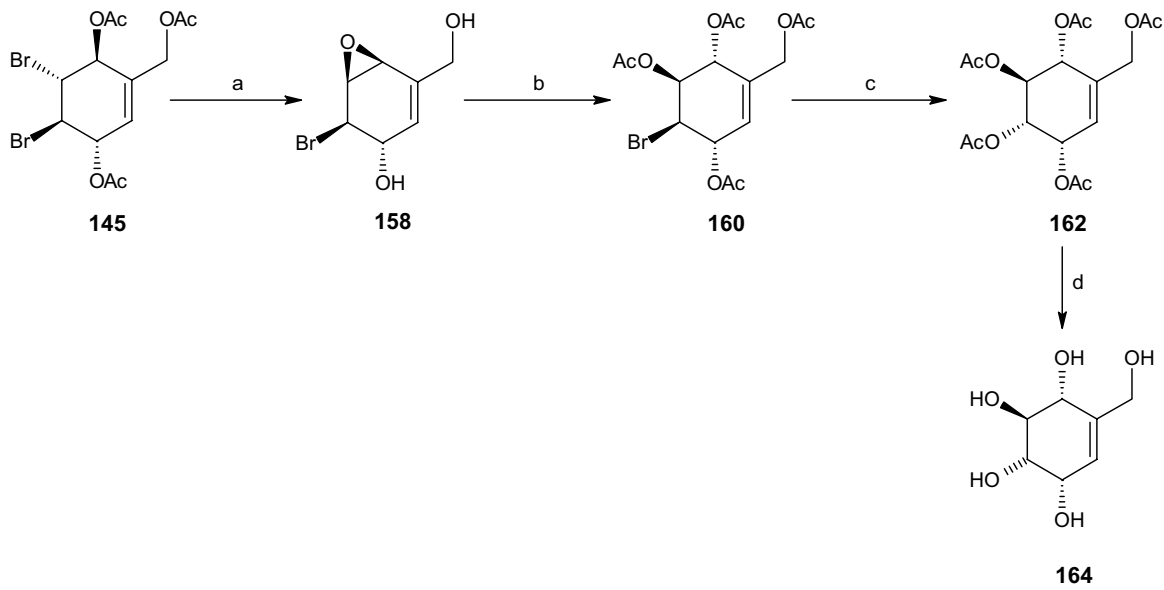

Scheme 32 Synthesis of rac-streptol (164). Reagents and conditions: a $\mathrm{LiOH}, \mathrm{Et}_{2} \mathrm{O} / \mathrm{MeOH}, 83 \%$ yield, b p-TSA, $\mathrm{H}_{2} \mathrm{O}, \mathrm{Ac}_{2} \mathrm{O}, \mathrm{C}_{5} \mathrm{H}_{5} \mathrm{~N}, 51 \%$ yield, c $\mathrm{AgOAc}, \mathrm{AcOH}, \mathrm{Ac}_{2} \mathrm{O}, \mathrm{C}_{5} \mathrm{H}_{5} \mathrm{~N}, 65 \%$ yield, d $\mathrm{NaOMe}, \mathrm{MeOH}$, $81 \%$ yield

acetate in $90 \%$ aqueous acetic acid) alongside acetylation with acetic anhydride and pyridine, yielding 35\% and 32\% of compounds 154 and 155 (Schemes 30, $31)$, respectively. These two compounds were then converted into their corresponding alcohol compounds, rac-MK7607 (156, 82\% yield) and 157 (88\% yield) [16].

\subsubsection{Synthesis of Streptol}

Streptol (164) can be obtained from intermediate compound 145 in four steps, starting with the formation of an epoxide from the trans bromide and acetoxy group via addition of lithium hydroxide in $\mathrm{Et}_{2} \mathrm{O}$ and methanol, preserving relative configuration at $\mathrm{C} 4$ and $\mathrm{C} 5$ and yielding epoxide $\mathbf{1 5 8}$ (83\% yield). Nucleophilic ring opening in water, followed by acetylation, yielded $51 \%$ of bromide diacetate $\mathbf{1 6 0}$. Inversion and acetylation of the bromide group resulted in penta-acetate 162. Deacetylation of 162 with methanolic sodium provided the desired rac-streptol (164) with an $81 \%$ yield (Scheme 32) [16].

\subsubsection{Synthesis of Unsaturated Pentaol 165}

Similar to Scheme 32, the synthesis from compound 149 began with epoxidation to 159 (Scheme 33). Ring opening occurred through the addition of carbon tetrabromide in water, followed by acetylation, yielding $37 \%$ of the bromide triacetate compound 161. Through bromide displacement by acetate, the authors obtained the methyl tetraol 165 (Scheme 33) with the same relative configuration as streptol (164) [16]. 


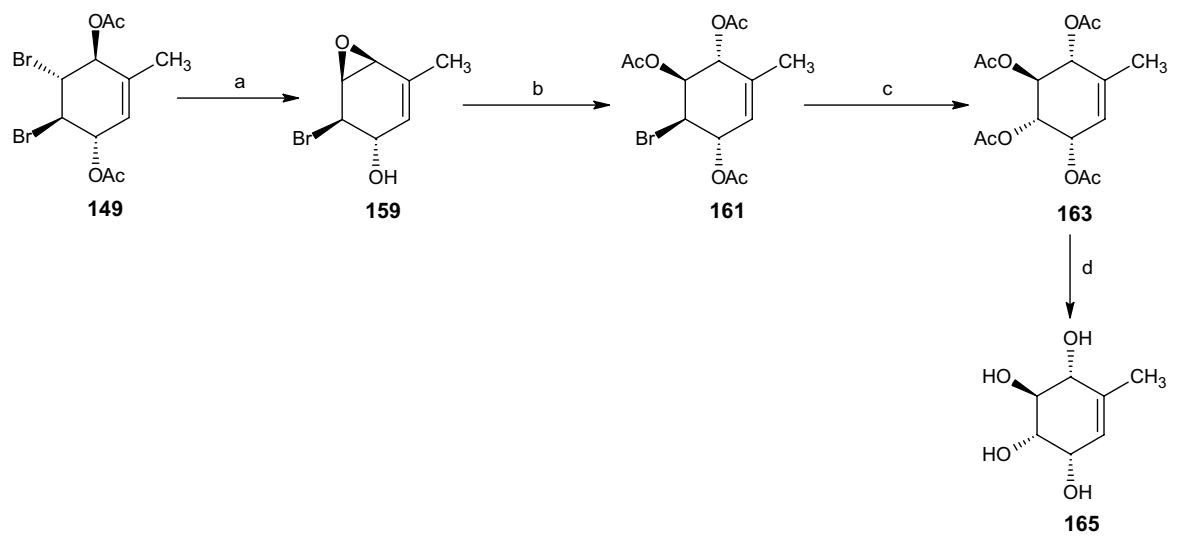

Scheme 33 Synthesis of racemic tetraol 165. Reagents and conditions: a $\mathrm{LiOH}, \mathrm{Et}_{2} \mathrm{O} / \mathrm{MeOH}, 72 \%$ yield, b $\mathrm{CBr}_{4}, \mathrm{H}_{2} \mathrm{O}, \mathrm{Ac}_{2} \mathrm{O}, \mathrm{C}_{5} \mathrm{H}_{5} \mathrm{~N}, 37 \%$ yield, c AgOAc, $\mathrm{AcOH}, \mathrm{Ac}_{2} \mathrm{O}, \mathrm{C}_{5} \mathrm{H}_{5} \mathrm{~N}, 38 \%$ yield, d $\mathrm{NaOMe}, \mathrm{MeOH}$, $88 \%$ yield

\subsubsection{Synthesis of Unsaturated Pentaol 171}

The last pentaol compound was obtained in six steps (Scheme 34). Initially, intermediate 145 was deacetylated using potassium carbonate in methanol, resulting in dibromide diol 166, whose vicinal hydroxyl groups were protected using 2,2-DMP and p-TSA in acetone, ultimately yielding 100\% acetonide 167. Epoxidation occurred via the addition of sodium hydroxide in Et $2 \mathrm{O}$ and water with a $52 \%$ yield of epoxide $\mathbf{1 6 8}$, followed by deprotection and acetylation comparable to those described in earlier pathways, yielding $52 \%$ of bromide tetra acetate 169. The Woodward reaction conditions [47] ensured inversion and acetylation

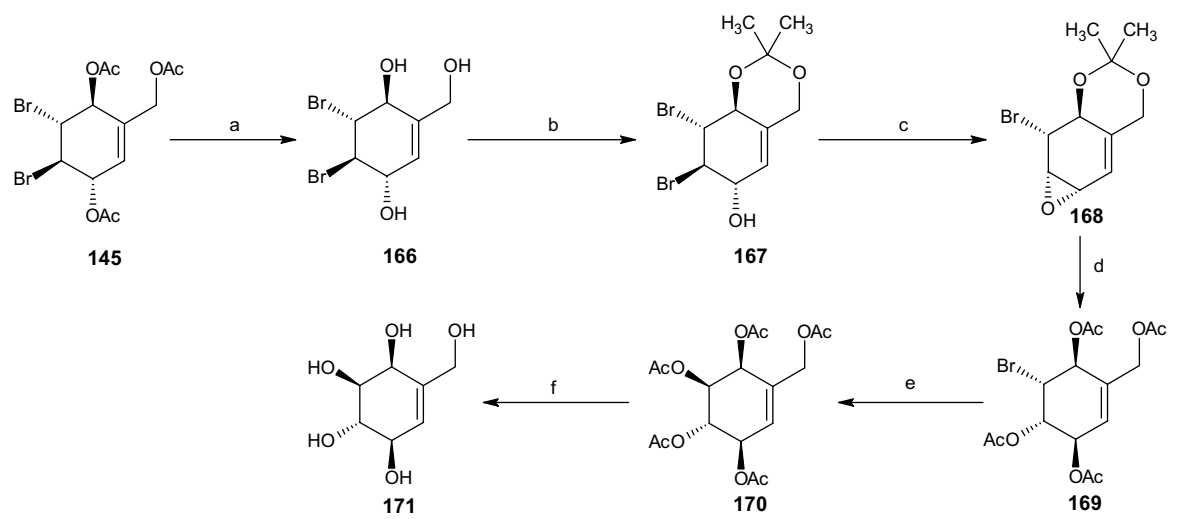

Scheme 34 Synthesis of racemic pentaol 171. Reagents and conditions: a $\mathrm{K}_{2} \mathrm{CO}_{3}, \mathrm{MeOH}, 100 \%$ yield, b 2,2-DMP, $p$-TSA, acetone, $100 \%$ yield, c NaOH, $\mathrm{Et}_{2} \mathrm{O} / \mathrm{H}_{2} \mathrm{O}, 52 \%$ yield, d AcOH, $\mathrm{H}_{2} \mathrm{O}, \mathrm{Ac}_{2} \mathrm{O}, \mathrm{C}_{5} \mathrm{H}_{5} \mathrm{~N}$, $52 \%$ yield, e AgOAc, $\mathrm{AcOH}, \mathrm{Ac}_{2} \mathrm{O}, \mathrm{C}_{5} \mathrm{H}_{5} \mathrm{~N}, 54 \%$ yield, f $\mathrm{NaOMe}, \mathrm{MeOH}, 79 \%$ yield 
producing penta-acetate $\mathbf{1 7 0}$ in $54 \%$ yield. Finally, the deprotection of compound $\mathbf{1 7 0}$ yielded $79 \%$ of the desired unsaturated pentaol 171 [16].

\section{Summary}

The present review highlights the success of carbasugar synthesis from non-sugar compounds. Due to their structural and configuration similarities with the desired products, the reactants used were able to deliver the products in few synthetic steps with comparatively high efficiency. These results suggest that future experiments may permit generation of the same products even faster and with higher yields. Due to the great diversity in the structures already known, the road is now paved for successful research in chemical and clinical medicine, including HIV and tumor treatment $[14,53,54]$. Due to the growing population and prevalence of common diseases, the importance of pseudo-sugar synthesis is greater than ever before. Ultimately, the synthetic routes described in this review offer information on already successful research and provide an impetus for the development of new discoveries in the field of carbasugars.

Acknowledgement We like to thank the ReAching program of the faculty MLS, Furtwangen University, for support.

Author Contributions AZ, LK, and TM performed the literature search. The manuscript was written together by AZ, LK, and MSS. The tables and images were produced by AZ and LK. The complete writing, design, and corrections of the manuscript were led and supervised by MSS and H-PD. All authors have read and agreed to the published version of the manuscript.

Funding Open Access funding enabled and organized by Projekt DEAL. We are grateful for support within the Forschungstandem program awarded by the Institute of Applied Research (IAF), Furtwangen University (VS-Schwenningen, Germany).

\section{Declarations}

Conflict of interest The authors declare that there is no conflict of interest.

Institutional review board statement Not applicable.

Informed consent statement Not applicable.

Open Access This article is licensed under a Creative Commons Attribution 4.0 International License, which permits use, sharing, adaptation, distribution and reproduction in any medium or format, as long as you give appropriate credit to the original author(s) and the source, provide a link to the Creative Commons licence, and indicate if changes were made. The images or other third party material in this article are included in the article's Creative Commons licence, unless indicated otherwise in a credit line to the material. If material is not included in the article's Creative Commons licence and your intended use is not permitted by statutory regulation or exceeds the permitted use, you will need to obtain permission directly from the copyright holder. To view a copy of this licence, visit http://creativecommons.org/ licenses/by/4.0/. 


\section{References}

1. Demchenko AV (2005) Best synthetic methods: carbohydrates. Carbohydr Res 340:173-174. https://doi.org/10.1016/j.carres.2004.10.010

2. Nokami T, Saito K, Yoshida J (2012) Synthetic carbohydrate research based on organic electrochemistry. Carbohydr Res 363:1-6. https://doi.org/10.1016/j.carres.2012.09.023

3. Sturgeon RJ (2003) Advances in macromolecular carbohydrate research. JAI, Amsterdam

4. Varki A, Cummings RD, Esko JD et al (eds) (2017) Essentials of glycobiology, 3rd edn. Cold Spring Harbor Laboratory Press, Cold Spring Harbor

5. Fraser-Reid BO, Tatsuta K, Thiem J (2008) Glycoscience: chemistry and chemical biology; with 159 tables, 2nd edn. Springer, Berlin

6. Gabius H-J, Siebert H-C, André S et al (2004) Chemical biology of the sugar code. ChemBioChem 5:740-764. https://doi.org/10.1002/cbic.200300753

7. Osborn HMI, Evans PG, Gemmell N et al (2004) Carbohydrate-based therapeutics. J Pharm Pharmacol 56:691-702. https://doi.org/10.1211/0022357023619

8. McCasland GE, Furuta S, Durham LJ (1966) Alicyclic carbohydrates. XXIX. 1,2 The synthesis of a pseudo-hexose (2,3,4,5-tetrahydroxycyclohexanemethanol). J Org Chem 31:1516-1521. https://doi. org/10.1021/jo01343a048

9. Block O, Klein G, Altenbach HJ et al (2000) New stereoselective route to the epoxyquinol core of manumycin-type natural products. Synthesis of enantiopure (+)-bromoxone, (-)-LL-C10037 alpha, and (+)-KT 8110. J Org Chem 65:716-721. https://doi.org/10.1021/jo991324c

10. McCasland GE, Furuta S, Durham LJ (1968) Alicyclic carbohydrates. 33. Epimerization of pseudoalpha-DL-talopyranose to pseudo-alpha-DL-galactopyranose. Proton magnetic resonance studies. J Org Chem 33:2841-2844. https://doi.org/10.1021/jo01271a050

11. Miller TW, Arison BH, Albers-Schonberg G (1973) Isolation of a cyclitol antibiotic: 2,3,4,5-tetrahydroxycyclohexanemethanol. Biotechnol Bioeng 15:1075-1080. https://doi.org/10.1002/bit. 260150606

12. Arjona O, Gómez AM, López JC et al (2007) Synthesis and conformational and biological aspects of carbasugars. Chem Rev 107:1919-2036. https://doi.org/10.1021/cr0203701

13. Roscales S, Plumet J (2016) Biosynthesis and biological activity of carbasugars. Int J Carbohydr Chem 2016:1-42. https://doi.org/10.1155/2016/4760548

14. Awolade P, Cele N, Kerru N et al (2020) Therapeutic significance of $\beta$-glucuronidase activity and its inhibitors: a review. Eur J Med Chem 187:1119-1121. https://doi.org/10.1016/j.ejmech.2019. 111921

15. Lahiri R, Ansari AA, Vankar YD (2013) Recent developments in design and synthesis of bicyclic azasugars, carbasugars and related molecules as glycosidase inhibitors. Chem Soc Rev 42:51025118. https://doi.org/10.1039/C3CS35525J

16. Leermann T, Block O, Podeschwa MAL et al (2010) De novo synthesis and lectin binding studies of unsaturated carba-pyranoses. Org Biomol Chem 8:3965-3974. https://doi.org/10.1039/C003597A

17. Babczyk A, Wingen LM, Menche D (2020) Optimized and scalable synthesis of carba- $\alpha-\mathrm{d}-\mathrm{glu}-$ cosamine. Eur J Org Chem 2020:6645-6648. https://doi.org/10.1002/ejoc.202001203

18. Lünse CE, Schmidt MS, Wittmann V et al (2011) Carba-sugars activate the glmS-riboswitch of Staphylococcus aureus. ACS Chem Biol 6:675-678. https://doi.org/10.1021/cb200016d

19. Ng W-L, Li H-C, Lau K-M et al (2017) Concise and stereodivergent synthesis of carbasugars reveals unexpected structure-activity relationship (SAR) of SGLT2 inhibition. Sci Rep 7:5581. https://doi. org/10.1038/s41598-017-05895-9

20. Callam CS, Lowary TL (2001) Synthesis and conformational investigation of methyl 4a-carba-Darabinofuranosides. J Org Chem 66:8961-8972. https://doi.org/10.1021/jo010827r

21. Callam CS, Lowary TL (2000) Total synthesis of both methyl 4a-carba-D-arabinofuranosides. Org Lett 2:167-169. https://doi.org/10.1021/o19912682

22. Jiang S, Singh G, Batsanov AS (2000) Synthesis of a difluorinated carbasugar from d-ribose via intramolecular nitrone cycloaddition reaction. Tetrahedron Asymmetry 11:3873-3877. https://doi. org/10.1016/S0957-4166(00)00367-0

23. Babu DC, Rao CB, Venkatesham K et al (2014) Toward synthesis of carbasugars (+)-gabosine C, (+)-COTC, (+)-pericosine B, and (+)-pericosine C. Carbohydr Res 388:130-137. https://doi.org/ 10.1016/j.carres.2013.08.008 
24. Banachowicz P, Buda S (2019) Gram-scale carbasugar synthesis via intramolecular seleno-Michael/ aldol reaction. RSC Adv 9:12928-12935. https://doi.org/10.1039/C9RA02002K

25. Chen Y-L, Redlich H, Bergander K et al (2007) D-Glucosamine trimethylene dithioacetal derivatives: formation of six- and seven-membered ring amino carbasugars. Synthesis of (-)-calystegine B3. Org Biomol Chem 5:3330-3339. https://doi.org/10.1039/b711112f

26. Cheng X, Khan N, Kumaran G et al (2001) A convergent strategy for the synthesis of beta-carbagalacto-disaccharides. Org Lett 3:1323-1325. https://doi.org/10.1021/o10156906

27. Li Q, Yuan F, Zhou C et al (2010) Free-radical ring closure to conformationally locked $\alpha$-L-carbaLNAs and synthesis of their oligos: nuclease stability, target RNA specificity, and elicitation of RNase H. J Org Chem 75:6122-6140. https://doi.org/10.1021/jo100900v

28. Blériot Y, Giroult A, Mallet J-M et al (2002) Synthesis of seven- and eight-membered carbasugar analogs via ring-closing metathesis and their inhibitory activities toward glycosidases. Tetrahedron Asymmetry 13:2553-2565. https://doi.org/10.1016/S0957-4166(02)00654-7

29. Sun Y, Nitz M (2012) Syntheses of carbocyclic analogues of $\alpha$-D-glucosamine, $\alpha$-D-mannose, $\alpha$-D-mannuronic acid, $\beta$-L-idosamine, and $\beta$-L-gulose. J Org Chem 77:7401-7410. https://doi.org/ 10.1021/jo301240j

30. Numata A, Iritani M, Yamada T et al (1997) Novel antitumour metabolites produced by a fungal strain from a sea hare. Tetrahedron Lett 38:8215-8218. https://doi.org/10.1016/S0040-4039(97) 10198-8

31. Numata A, Takahashi C, Ito Y et al (1996) Penochalasins, a novel class of cytotoxic cytochalasans from a Penicillium species separated from a marine alga: structure determination and solution conformation. J Chem Soc Perkin Trans I:239. https://doi.org/10.1039/p19960000239

32. Donohoe TJ, Blades K, Helliwell M et al (1998) The synthesis of (+)-pericosine B. Tetrahedron Lett 39:8755-8758. https://doi.org/10.1016/S0040-4039(98)01989-3

33. Yamada T, Iritani M, Ohishi H et al (2007) Pericosines, antitumour metabolites from the sea hare-derived fungus Periconia byssoides. Structures and biological activities. Org Biomol Chem 5:3979-3986. https://doi.org/10.1039/B713060K

34. Boyd DR, Sharma ND, Acaru CA et al (2010) Chemoenzymatic synthesis of carbasugars (+)-pericosines A-C from diverse aromatic cis-dihydrodiol precursors. Org Lett 12:2206-2209. https://doi.org/10.1021/ol100525r

35. Vitelio C, Bellomo A, Brovetto M et al (2004) Concise chemoenzymatic synthesis of epi-inositol. Carbohydr Res 339:1773-1778

36. Franke D, Lorbach V, Esser S et al (2003) (S, S)-2,3-Dihydroxy-2,3-dihydrobenzoic acid: microbial access with engineered cells of Escherichia coli and application as starting material in natural-product synthesis. Chemistry 9:4188-4196. https://doi.org/10.1002/chem.200204265

37. Mehta G, Mohal N, Lakshminath S (2000) A norbornyl route to cyclohexitols: structural diversity in fragmentation through functional group switching. Synthesis of $\alpha$ - and $\beta$-galactose, $\alpha$-talose and $\alpha$-fucopyranose carbasugars. Tetrahedron Lett 41:3505-3508. https://doi.org/10. 1016/S0040-4039(00)00408-1

38. Diels O, Alder K (1928) Synthesen in der hydroaromatischen Reihe. Justus Liebigs Ann Chem 460:98-122. https://doi.org/10.1002/jlac.19284600106

39. Jana CK, Studer A (2007) Divergente Reaktionen an Racematen: katalytische, enantioselektive und regiodivergente Nitroso-Diels-Alder-Reaktionen. Angew Chem 119:6662-6664. https://doi. org/10.1002/ange.200701631

40. Takahashi T, Kotsubo H, Lyobe A et al (1990) A new synthetic approach to pseudo-sugars by asymmetric Diels-Alder reaction. Synthesis of optically pure pseudo- $\beta$-D-mannopyranose, 1 -amino-1 -deoxypseudo- $\alpha$-D-mannopyranose and pseudo- $\alpha$-L-mannopyranose derivatives. J Chem Soc Perkin Trans 1:3065-3072. https://doi.org/10.1039/P19900003065

41. Böhm M (2005) Zum Wirkmechanismus konfigurationserhaltender $\beta$-Glycosidasen Isochinuclidine als Mimetika eines reaktiven Konformeren sowie Synthese von 1-Amino-1-desoxy-carbazuckern. PhD thesis, ETH Zurich

42. Suami T, Ogawa S, Nakamoto K et al (1977) Synthesis of penta-N, O-acetyl-DL-validamine. Carbohydr Res 58:240-244. https://doi.org/10.1016/S0008-6215(00)83425-4

43. Boyd DR, Sharma ND, Llamas NM et al (2005) Chemoenzymatic synthesis of carbasugars from iodobenzene. Org Biomol Chem 3:1953-1963. https://doi.org/10.1039/b502009c

44. Block O (2000) Darstellung von Verbindungen vom Manumycin-Typ sowie von Zuckeranaloga aus unverzweigtem und verzweigtem p-Benzochinon. PhD Thesis, Bergische Universität-Gesamthochschule Wuppertal 
45. Podeschwa MAL (2003) Synthese von Naturstoffen auf Inositolbasis ausgehend von para-Benzochinon. PhD Thesis, Bergische Universität Wuppertal

46. Boyd DR, Sharma ND, Barr SA et al (1994) Chemoenzymic synthesis of the 2,3- and 3,4-cisdihydrodiol enantiomers of monosubstituted Benzenes. J Am Chem Soc 116:1147-1148. https:// doi.org/10.1021/ja00082a053

47. Woodward RB, Brutcher FV (1958) cis-Hydroxylation of a synthetic steroid intermediate with iodine, silver acetate and wet acetic acid. J Am Chem Soc 80:209-211. https://doi.org/10.1021/ ja01534a053

48. Banwell MG, Bray AM, Wong DJ (2001) A concise and chemoenzymatic synthesis of (-)-gabosine A, a carba-sugar enone from Streptomycetes. New J Chem 25:1351-1354. https://doi.org/10. $1039 / \mathrm{b} 106419 \mathrm{c}$

49. VanRheenen V, Kelly RC, Cha DY (1976) An improved catalytic OsO4 oxidation of olefins to cis1,2-glycols using tertiary amine oxides as the oxidant. Tetrahedron Lett 17:1973-1976. https://doi. org/10.1016/S0040-4039(00)78093-2

50. Cahiez G, Avedissian H (1998) Highly stereo and chemoselective iron-catalyzed alkenylation of organomagnesium compounds. Synthesis 1998:1199-1205. https://doi.org/10.1055/s-1998-2135

51. Boyd DR, Sharma ND, Bowers NI et al (2010) Chemoenzymatic synthesis of the carbasugars carba-beta-L-galactopyranose, carba-beta-L-talopyranose and carba-alpha-L-talopyranose from methyl benzoate. Org Biomol Chem 8:1415-1423. https://doi.org/10.1039/b921545j

52. Prévost C (1933) C R Hebd Seances Acad Sci 196:1129

53. Hamon N, Slusarczyk M, Serpi M et al (2015) Synthesis and biological evaluation of phosphoramidate prodrugs of two analogues of 2-deoxy-d-ribose-1-phosphate directed to the discovery of two carbasugars as new potential anti-HIV leads. Bioorg Med Chem 23:829-838. https://doi.org/10. 1016/j.bmc.2014.12.039

54. Sadraei SI, Reynolds MR, Trant JF (2017) The synthesis and biological characterization of acetalfree mimics of the tumor-associated carbohydrate antigens. Adv Carbohydr Chem Biochem 74:137-237

Publisher's Note Springer Nature remains neutral with regard to jurisdictional claims in published maps and institutional affiliations. 